\title{
A Semi-Empirical Chlorophyll-a Retrieval Algorithm Considering the Effects of Sun Glint, Bottom Reflectance, and Non-Algal Particles in the Optically Shallow Water Zones of Sanya Bay Using SPOT6 Data
}

\author{
Yan $\mathrm{Yu}^{1}$, Shengbo Chen ${ }^{1, *}$, Wenhan Qin ${ }^{1}$, Tianqi $\mathrm{Lu}^{2}{ }^{2}$, Jian $\mathrm{Li}^{1}$ and Yijing Cao ${ }^{1}$ \\ 1 College of Geo-exploration Science and Technology, Jilin University, Changchun 130026, China; \\ yuyan14@mails.jlu.edu.cn (Y.Y.); qinwenhan@jlu.edu.cn (W.Q.); orinatureli@jlu.edu.cn (J.L.); \\ caoyj15@mails.jlu.edu.cn (Y.C.) \\ 2 Guangzhou Marine Geological Survey, China Geological Survey, Guangzhou 510075, China; \\ lutq17@mails.jlu.edu.cn \\ * Correspondence: chensb@jlu.edu.cn
}

Received: 27 July 2020; Accepted: 20 August 2020; Published: 26 August 2020

\begin{abstract}
Chlorophyll-a (Chl-a) concentration retrieval is essential for water quality monitoring, aquaculture, and guiding coastline infrastructure construction. Compared with common ocean color satellites, land observation satellites have the advantage of a higher resolution and more data sources for retrieving the concentration of Chl-a from optically shallow waters. However, the sun glint $\left(R_{\mathrm{sg}}\right)$, bottom reflectance $\left(R_{\mathrm{b}}\right)$, and non-algal particle (NAP) derived from terrigenous matter affect the accuracy of Chl-a concentration retrieval using land observation satellite image data. In this paper, we propose a semi-empirical algorithm based on the remote sensing reflectance $\left(R_{\mathrm{rs}}\right)$ of SPOT6 to retrieve the Chl-a concentration in Sanya Bay (SYB), considering the effect of $R_{\mathrm{sg}}, R_{\mathrm{b}}$, and NAP. In this semi-empirical algorithm, the Cox-Munk anisotropic model and radiative transfer model (RTM) were used to reduce the effects of $R_{\mathrm{sg}}$ and $R_{\mathrm{b}}$ on $R_{\mathrm{rs}}$, and the Chl-a concentration was retrieved by the Chl-a absorption coefficient at $490 \mathrm{~nm}\left(a_{\text {phy }}(490)\right)$ to remove the effect of NAP. The semi-empirical algorithm was in the form of Chl-a $=43.3\left[a_{\text {phy }}(490)\right]^{1.454}$, where $a_{\text {phy }}(490)$ was calculated by the total absorption coefficient and the absorption coefficients of each component by empirical algorithms. The results of the Chl-a concentration retrieval show the following: (1) SPOT6 data are available for Chl-a retrieval using this semi-empirical algorithm in oligotrophic or mesotrophic coastal waters, and the accuracy of the algorithm can be improved by removing the effects of $R_{\mathrm{sg}}, R_{\mathrm{b}}$, and NAP ( $\mathrm{R}^{2}$ from 0.71 to 0.93 and root mean square error (RMSE) from 0.23 to $0.11 \mathrm{ug} / \mathrm{L}$ ); (2) empirical algorithms based on the blue-green band are suitable for oligotrophic or mesotrophic coastal waters, and the algorithm based on the blue-green band difference Chl-a index (DCI) has stronger anti-interference in terms of the effects of sun glint and bottom reflectance than the algorithm based on the blue-green ratio (BGr); (3) in the case of ignoring $R_{\mathrm{sg}}$ unrelated to inherent optical properties (IOPs), NAP is the biggest interference factor when $>9.5 \mathrm{mg} / \mathrm{L}$ and the effect of bottom reflectance should be considered when the water depth $(H)<5 \mathrm{~m}$ in SYB; and (4) the inherent optical properties of the waters in SYB are dominated by NAP $(\mathrm{Chl}-\mathrm{a}=0.2-2.6 \mathrm{ug} / \mathrm{L}$ and NAP $=2.2-30.1 \mathrm{mg} / \mathrm{L})$, and the nutrients are concentrated by enclosed terrain and southeast current. This semi-empirical algorithm for Chl-a concentration retrieval has the potential to monitor Chl-a in oligotrophic and mesotrophic coastal waters using other land observation satellites (e.g., Landsat8 OLI, ASTER, and GaoFen2).
\end{abstract}

Keywords: coastal waters; land observation satellite; water quality monitoring; blue-green band; remote sensing; oligotrophic; mesotrophic 


\section{Introduction}

Though coastal zones only cover $2 \%$ of the world's land area, almost two-thirds of urban settlements with a population higher than 5 million live in these areas [1]. In particular, the optically shallow regions of coastal waters have the most diverse marine life and are significant for aquaculture and tourism. Monitoring the concentration of chlorophyll-a (Chl-a) in coastal waters by using ocean color satellites (e.g., SeaWiFs, MODIS, SeaWiFS, and MERIS) is one of the critical methods for water quality monitoring [2,3]. However, the retrieval of Chl-a concentration from optically shallow waters requires satellites with a higher spatial resolution. Therefore, the multi-spectral land observation satellites (e.g., SPOT6, Landsat8 OLI, ASTER, and GaoFen2) may have the a potential to retrieve Chl-a concentration from optically shallow waters.

According to the Chl-a absorption characteristics and band sets of satellites, selection of the best bands and different algorithms is a continuously hot research topic. For Case- 1 waters without terrigenous matter inputs (i.e., sediments and colored dissolved organic matter (CDOM)) or resuspended sediments, the optical properties of the ocean waters are tightly subordinated to the abundance of pigmented algal cells $[4,5]$. According to the optically characteristics of oceanic waters, the bio-optical algorithms based on the blue-green band-ratio (BGr) are suitable for oligotrophic waters [6-8]. According to the absorption peak of Chl-a near $440 \mathrm{~nm}$, the blue band at $443 \mathrm{~nm}$ was adopted in the early BGr algorithm [9]. To minimize the interference of the strong absorption of CDOM in the blue band, using in the algorithms based on BGr (e.g., SeaWiFS OC3, OC4, and MODIS OC3M), the blue band was red-shifted from $440 \mathrm{~nm}$ to $490 \mathrm{~nm}$ or $510 \mathrm{~nm}$ [10-12]. Though the Chl-a retrieval algorithm for Case- 1 waters is relatively mature and there are several algorithms working showing how to estimate from Case-2 waters, the band selection for Chl-a retrieval is still a difficult task in waters with complex constituents [13,14].

With the inflow of terrigenous matter from the runoff and the resuspension of bottom sediment, non-algal particle (NAP) is the main interfering factor for Chl-a retrieval in optically complex waters (i.e., Case 2 waters). The quasi-analytical algorithm (QAA) [15] based on the visible bands and the empirical or semi-empirical algorithm based on the near-infrared (NIR) bands (e.g., the three-band algorithm or the four-band algorithm) are effective in reducing the effects of CDOM and NAP interference in eutrophic waters [16-18]. However, for most land observation satellites (e.g., SPOT6, Landsat8 OLI, ASTER, and GaoFen2), the spectral resolution and the lack of NIR band near $705 \mathrm{~nm}$ do not meet the requirements of the QAA algorithm and algorithms based on the NIR band. However, for mesotrophic or oligotrophic waters, the low reflectance may cause a reduction in the signal-to-noise ratio (SNR) and, based on the BGr, both MERIS OC3E and OC4E perform better than algorithms based on NIR bands [14]. However, the spectral resolution and the lack of NIR band near $705 \mathrm{~nm}$ of land observation satellites (e.g., SPOT6, Landsat8 OLI, ASTER, and GaoFen2) do not meet the requirements of the QAA algorithm. The empirical or semi-empirical algorithms based on the near-infrared (NIR) bands are effective in reducing the effects of CDOM and NAP interference in eutrophic waters [19-21]. For land observation satellites, the lack of NIR band near $705 \mathrm{~nm}$ limits the ability of Chl-a retrieval in Case-2 waters. However, for mesotrophic or oligotrophic waters, the low reflectance may cause a reduction in the SNR, and algorithms based on the BGr, both MERIS OC3E and OC4E, perform better than algorithms based on NIR bands [14]. The two-rand-ratio (2Br) algorithm using Landsat8 OLI performs well in Case-2 waters [22-24]. Therefore, algorithms based on visible bands have the potential to retrieve the concentration of Chl-a in coastal waters.

For optically shallow waters, the acquisition of remote sensing reflectance or water-leaving reflectance $\left(R_{\mathrm{rs}}\right)$ is limited by the effects of boundary conditions, that is, sun glint and bottom reflectance. The contribution of sun glint to $R_{\mathrm{rs}}\left(R_{\mathrm{sg}}\right)$ mainly varies with the sun-satellite relative geometric relationship $[25,26]$. In the images of common ocean color sensors (e.g., MODIS, SeaWiFS, and MERIS), the trace of $R_{\mathrm{sg}}$ can be easily found because medium spatial resolution satellites have a wide field of view $[27,28]$. The view angle of sensors for coastal zone observation with high spatial resolution changes little, and sun glint may be ignored when the $R_{\mathrm{sg}}$ is lower than the water-leaving 
reflectance [29]. On the same remote sensing image, the $R_{\mathrm{sg}}$ changes with the wavelength owing to the variations of the water refractive index, and the difference of $R_{\mathrm{sg}}$ in the range of 350-2500 nm is approximately $10 \%$ [30,31]. The $R_{\mathrm{sg}}$ may cause a lot of errors, especially in clear waters with low reflectance. The method of removing sun glint by the near-infrared (NIR) band does well in oceanic waters with a low concentration of NAP, but it is not appropriate for coastal waters with a high concentration of NAP. The Cox-Munk analytical anisotropic model has previously been used to calculate the value of sun glint, but its applicability in areas with low $R_{\mathrm{sg}}$ still needs to be validated.

The water-leaving reflectance contributed by the bottom $\left(R_{\mathrm{bw}}\right)$ depends on the bottom reflectance and the water column attenuation coefficient. The type of bottom is the main factor for bottom reflectance, because the slope of the seafloor changes little in coastal zones. Bottom types mainly include sand, rock, mud, coral, and seagrass, which all result in an overestimation of the concentration of Chl-a because the reflectance of the green band is higher than that of the blue band. The radiative transfer model (RTM) has previously been used to calculate the $R_{\mathrm{bw}}$ [32-35], but the attenuation of the water column and the bottom reflectance need to be used as the input parameters.

Compared with ocean color satellites with moderate spatial resolution (e.g., MODIS, SeaWiFS, and MERIS), multi-spectral land observation satellites (e.g., SPOT6, Landsat8 OLI, ASTER, and GaoFen2) have the advantage of a higher resolution in reducing the effect of bottom. We chose SPOT6 data as an example. Although SPOT6 was not designed to be an ocean color sensor, SPOT6 image data have been widely used in land vegetation monitoring [36-38] and have the potential to be applied to Chl-a concentration retrieval in coastal waters. According to the band sets of SPOT6 (blue: 455-525 nm; red: $530-590 \mathrm{~nm}$ ) and $a_{\text {phy }}$ (shown in Figure A1), the blue and red bands reflect the absorption and reflection characteristics of $\mathrm{Chl}-\mathrm{a}$, respectively. Therefore, the blue-green band of SPOT6 data may have the potential to retrieve the concentration of Chl-a in oligotrophic or mesotrophic waters. However, it has a shortcoming in that broad-band spectral data are more sensitive to suspension than hyper-spectral data [39-41].

For Chl-a retrieval using broad-band spectral data in optically shallow waters of coastal waters, the main problems are the effects of sun-glint, bottom reflectance, and NAP. To solve these problems, we proposed a semi-empirical Chl-a retrieval algorithm combining the Cox-Munk anisotropic model [25,26], the RTM [32-35], and a bio-optical model. This semi-empirical algorithm has the potential to retrieve Chl-a using other broad-band spectral data without NIR band in mesotrophic and oligotrophic waters.

\section{Materials}

\subsection{Study Area}

Sanya Bay (SYB) is in the southeast of Hainan Island, the second-largest island in China (Figure 1), and lies in a tropical monsoon climate [42]. The coastline of Hainan Island mainly includes sandy, rocky, biological, and artificial coastlines. The coastline of the study area is a sandy coastline, and nearly no pollution has been found in this area. Most of the coastal waters of SYB are open water areas with large waves, and the mean monthly wave height is $0.87-1.87 \mathrm{~m}$ [43]. The water depth range is $0-35 \mathrm{~m}$ and there are many kinds of benthos and fishes in this study area.

The waters in the study area mainly include three types: ultraoligotrophic, oligotrophic, and mesotrophic waters. The water types vary with the ocean currents and the distance to the shore. The sea waves pick up large amounts of terrigenous particles from shallow waters and send them to the deep-water regions. The turbidity is very high within $2 \mathrm{~m}$ of the water depth, and the waters are as clear as oceanic waters when the depth is greater than $30 \mathrm{~m}$. The West Island mitigates the impact of the northeast current, which allows the southwest side of the island to retain a large amount of nutrients and sediment. On the southwest side of the West Island, the clear water and the wide shallow water region provide the best conditions for coral growth. Overall, the coastal waters of SYB are relatively clear and the optical properties are dominated by terrigenous suspended mineral particles. 


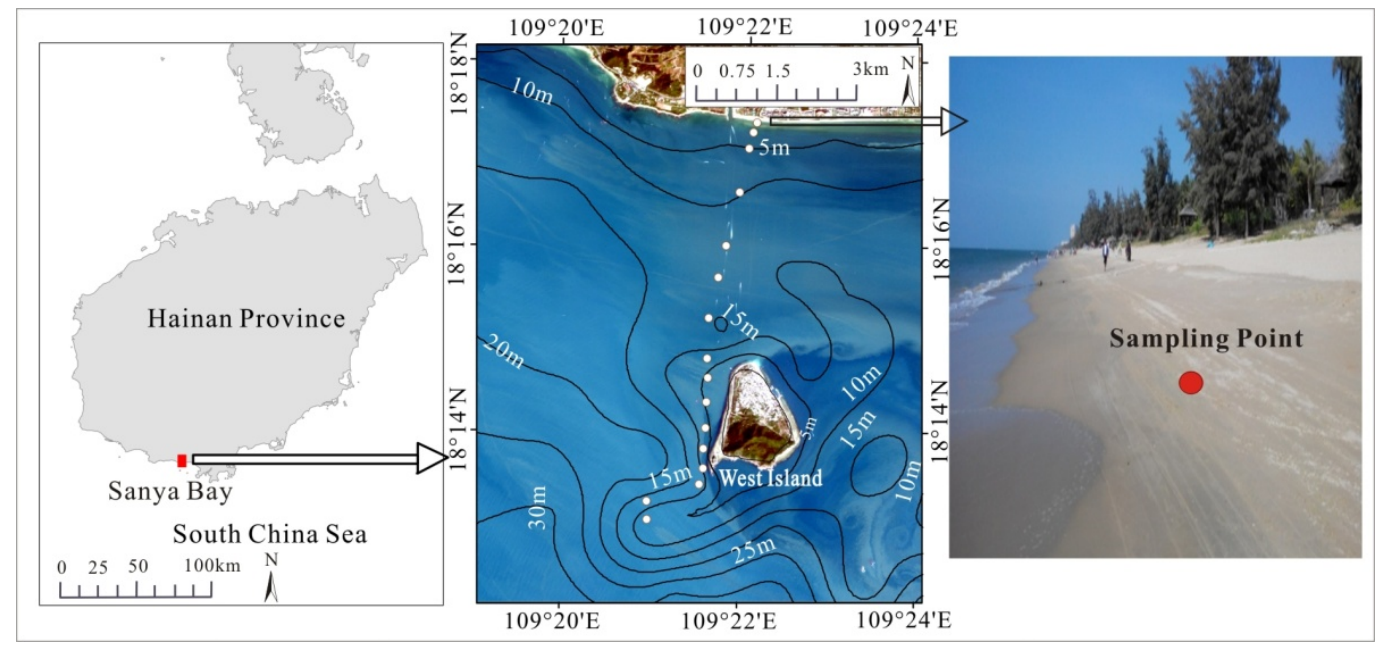

Figure 1. The geographic location of Sanya Bay, China. The white points in the SPOT6 image show the sampling locations of water. In the picture of the coast, the red point shows the sampling point of sand.

\subsection{SPOT6 Data}

SPOT6 data have three visible and near-infrared bands (wavelengths: $450-520 \mathrm{~nm} ; 530-590 \mathrm{~nm}$; $625-695 \mathrm{~nm}$; and 760-890 nm), and the spatial resolution is $6 \mathrm{~m}$. In the application of ocean color remote sensing, the visible bands, and the NIR bands are used for monitoring phytoplankton and non-algal particulars, respectively. Compared with other common ocean color satellites, the higher spatial resolution can help to analyze the changes of Chl-a in coastal zones. According to the band sets of SPOT6 (blue: $455-525 \mathrm{~nm}$; red: $530-590 \mathrm{~nm}$ ) and $a_{\text {phy }}$ (shown in Appendix A.1, Figure A1), the blue and red bands reflect the absorption and reflection characteristics of Chl-a, respectively. The image of SPOT6 was acquired on 21 January 2013.

\subsection{In Situ Measured Dataset}

The in situ measured parameters include wind speed, water depth, and water column parameters (i.e., Chl-a, NAP, and CDOM) (as shown in Table 1). The in-situ samples were collected on 23 January 2013. The wind speed data were obtained from the meteorological station of the China Meteorological Administration, and the acquisition time was at 11:00 on 1 January 2013. The water depth-measured data used the single-point sonar data measured by the Guangzhou Marine Geological Survey in November 2014. The Chl-a concentration was obtained through the extraction of a filtered sample ( $0.45 \mu \mathrm{m}$ What-man GF/F) with $90 \%$ acetone solution and the determination of the $a_{\text {phy }}$ with a Shimadzu UV-2600PC spectrophotometer. The CDOM absorption spectra were determined using a Shimadzu UV-2600PC spectrophotometer, fitted with a $1 \mathrm{~cm}$ quartz cuvette, in the spectral region between 200 and $800 \mathrm{~nm}$ at $1 \mathrm{~nm}$ intervals. The water samples for the CDOM measurement were filtered through a $0.7 \mu \mathrm{m}$ pre-combusted Whatman GF/F filter, and then through a $0.22 \mu \mathrm{m}$ Millipore membrane cellulose filter. The absorption coefficients of the NAP were measured by a UV2600 PC spectrophotometer based on the filter pad methodology, and the membrane was $0.7 \mu \mathrm{m}$ Whatman GF/F [23,44]. The measured absorption coefficients of Chl-a, CDOM, and NAP are shown in Figure 2. 
Table 1. The measured water column parameters for the model input include the absorption coefficients, the water constituent concentrations, and the water depths. NAP, non-algal particle.

\begin{tabular}{|c|c|c|c|c|c|c|c|c|c|}
\hline & $\begin{array}{l}\text { Wavelength } \\
\text { (nm) }\end{array}$ & $\begin{array}{c}a_{\text {phy }} \\
\left(\mathrm{m}^{-1}\right)\end{array}$ & $\begin{array}{l}a_{\text {NAP }} \\
\left(\mathrm{m}^{-1}\right)\end{array}$ & $\begin{array}{c}a_{\mathrm{CDOM}} \\
\left(\mathrm{m}^{-1}\right)\end{array}$ & $\begin{array}{c}a_{\mathrm{w}} \\
\left(\mathrm{m}^{-1}\right)\end{array}$ & $\begin{array}{c}b_{\mathrm{b}}{ }^{*} \text { NAP } \\
\left(\mathrm{m}^{2} \mathrm{~g}^{-1}\right)\end{array}$ & $\begin{array}{l}C h l-a \\
\text { (ug/L) }\end{array}$ & $\begin{array}{c}N A P \\
(\mathrm{mg} / \mathrm{L})\end{array}$ & $\begin{array}{c}H \\
(\mathrm{~m})\end{array}$ \\
\hline \multirow{3}{*}{ mean } & 490 & 0.034 & 0.1 & 0.037 & 0.019 & 0.0156 & \multirow{3}{*}{0.587} & \multirow{3}{*}{5.565} & \multirow{3}{*}{7.803} \\
\hline & 560 & 0.011 & 0.076 & 0.013 & 0.071 & 0.0150 & & & \\
\hline & 660 & 0.017 & 0.033 & 0.003 & 0.410 & 0.0141 & & & \\
\hline \multirow{3}{*}{$\max$} & 490 & 0.171 & 0.562 & 0.059 & - & & \multirow{3}{*}{1.952} & \multirow{3}{*}{23.570} & \multirow{3}{*}{15.000} \\
\hline & 560 & 0.039 & 0.218 & 0.021 & - & & & & \\
\hline & 660 & 0.063 & 0.151 & 0.005 & - & & & & \\
\hline \multirow{3}{*}{$\min$} & 490 & 0.023 & 0.02 & 0 & - & & \multirow{3}{*}{0.205} & \multirow{3}{*}{2.670} & \multirow{3}{*}{1.0} \\
\hline & 560 & 0.006 & 0.012 & 0 & - & & & & \\
\hline & 660 & 0.011 & 0.006 & 0 & - & & & & \\
\hline
\end{tabular}
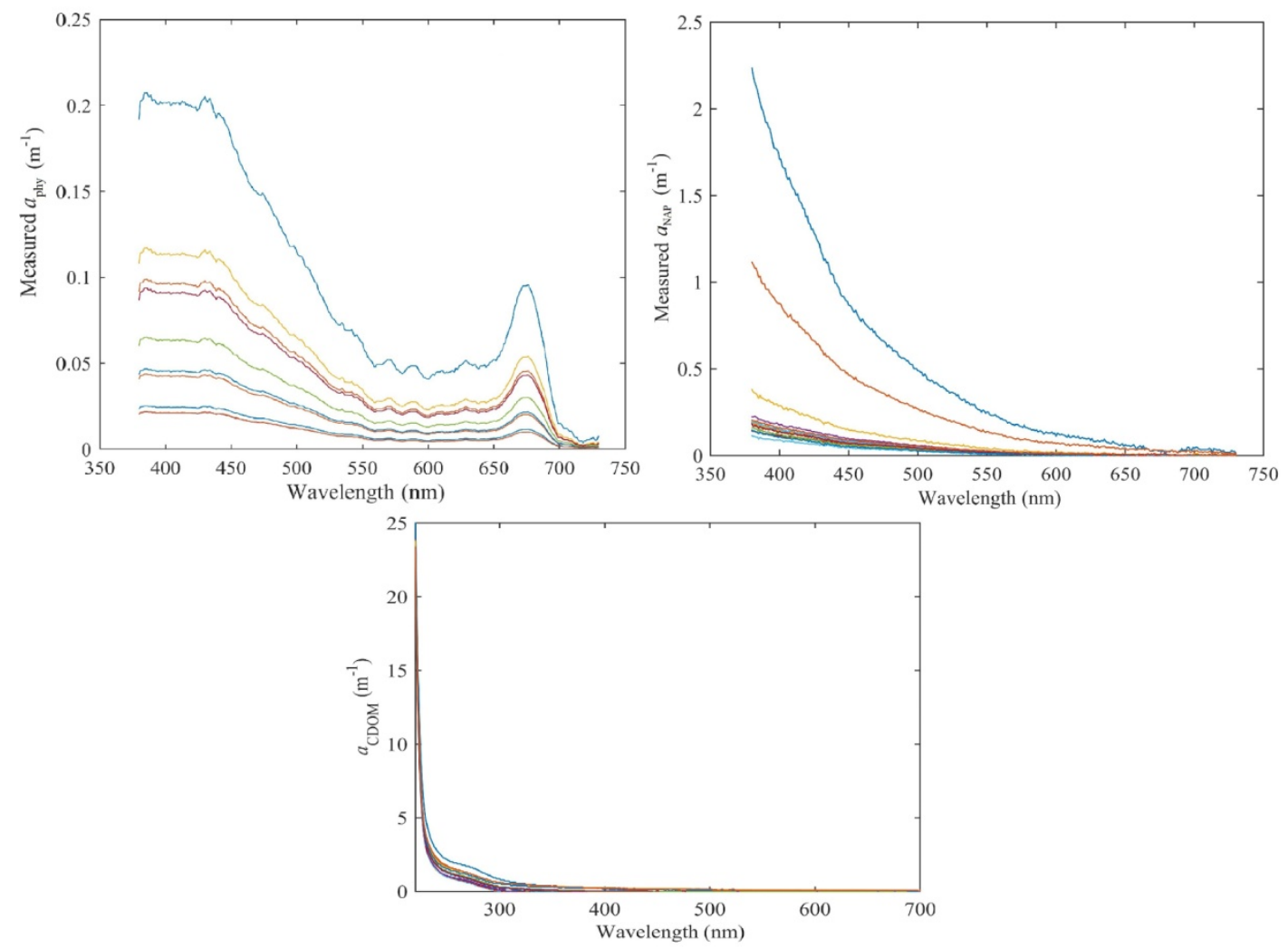

Figure 2. The measured absorption coefficients of chlorophyll-a (Chl-a), non-algal particle (NAP), and colored dissolved organic matter (CDOM).

The specific backscattering coefficient $\left(b_{\mathrm{b}}{ }^{*}\right)$ as input parameter for RTM can be calculated by the concentration of Chl-a and NAP, as well as their specific scattering coefficient ( $b^{*}$ phy and $b^{*}$ NAP) and backscattering ratio ( $B_{\text {phy }}$ and $\left.B_{\mathrm{NAP}}\right)$. The mean value of specific backscattering coefficient $\left(b^{*}\right)$ at $532 \mathrm{~nm}$ measured in mineral-dominated waters was $0.519 \mathrm{~m}^{2} \mathrm{~g}^{-1}$ [45] and the mean value of $b^{*}$ NAP after removing $b^{*}$ phy was $0.4 \mathrm{~m}^{2} \mathrm{~g}^{-1}$ [46]. The $B_{\mathrm{NAP}}$ at $488 \mathrm{~nm}$ ranged from 0.006 to 0.03 in Hudson Bay (Canada) with a relatively closed terrain and that measured in the English Channel with open terrain was 0.04 [46]. The $b_{\mathrm{b}}{ }^{*}$ phy ranges from 0.04 for macrophytoplankton to 0.005 for microphytoplankton [47]. For the total attenuation coefficient in coastal waters with Chl-a $<2 \mathrm{ug} / \mathrm{L}, b_{\mathrm{b}}{ }^{*}$ phy was a negligible quantity. The specific backscattering coefficient for NAP ( $b_{\mathrm{b}}{ }^{*}$ NAP) was calculated by $B_{\mathrm{NAP}}$ and $b^{*}$ NAP from Neil's datasets measured by HOBI Labs HS-2 backscattering meter $\left(B_{\mathrm{NAP}}=0.04\right.$ and $b^{*} \mathrm{NAP}=0.4 \mathrm{~m}^{2} \mathrm{~g}^{-1}$ at $\left.488 \mathrm{~nm}\right)[46]$. 


\section{Remote Sensing Reflectance Algorithm}

In optically deep waters, the remote sensing reflectance or leaving water reflectance $\left(R_{\mathrm{rs}}\right)$ is defined by the ratio of water-leaving radiance $\left(L_{\mathrm{w}}\right)$ to downward irradiance $\left(E_{\mathrm{d}}\right)$ [48]. However, $R_{\mathrm{rs}}$ in optically shallow waters is affected by bottom. The available Chl-a concentration retrieval algorithm is based on the acquirement of the accurate $R_{\text {rs }}$ (i.e., the remote sensing reflectance without the effect of the bottom). Although ocean color remote sensing has been studied for over half a century, the acquisition of accurate $R_{\mathrm{rs}}$ in optically shallow waters is still a challenge for Chl-a concentration retrieval $[2,9,33]$. After accurate atmospheric correction, the reflectance gathered by a sensor just above the water surface is referred to as apparent remote sensing reflectance $\left(R_{\mathrm{ap}}\right)$. In oceanic waters, $R_{\mathrm{ap}}$ is the sum of the sun glint (i.e., the specular reflectance $\left.\left(R_{\mathrm{sg}}\right)\right)$ and the reflectance contributed by the water column $\left(R_{\mathrm{cw}}\right)$, and the reflectance in the sun glint areas may be far larger than $R_{\mathrm{cw}}$. Although there are a number of novel models for sun glint calculation, the most common approach of the Cox-Munk model is still widely used [25-28]. In optically shallow waters, bottom reflectance is another boundary condition for the retrieval of $R_{\mathrm{rs}}$, and the reflectance contributed by the bottom $\left(R_{\mathrm{bw}}\right)$ can be calculated using the RTM [32-35]. Assuming atmospheric correction is available, in order to retrieve $R_{\mathrm{rs}}$ or $R_{\mathrm{cw}}$, knowledge of the propagation of light within a water body is necessary, and the boundary conditions and inherent optical properties (IOPs) are the main research objects (as shown in Figure 3).

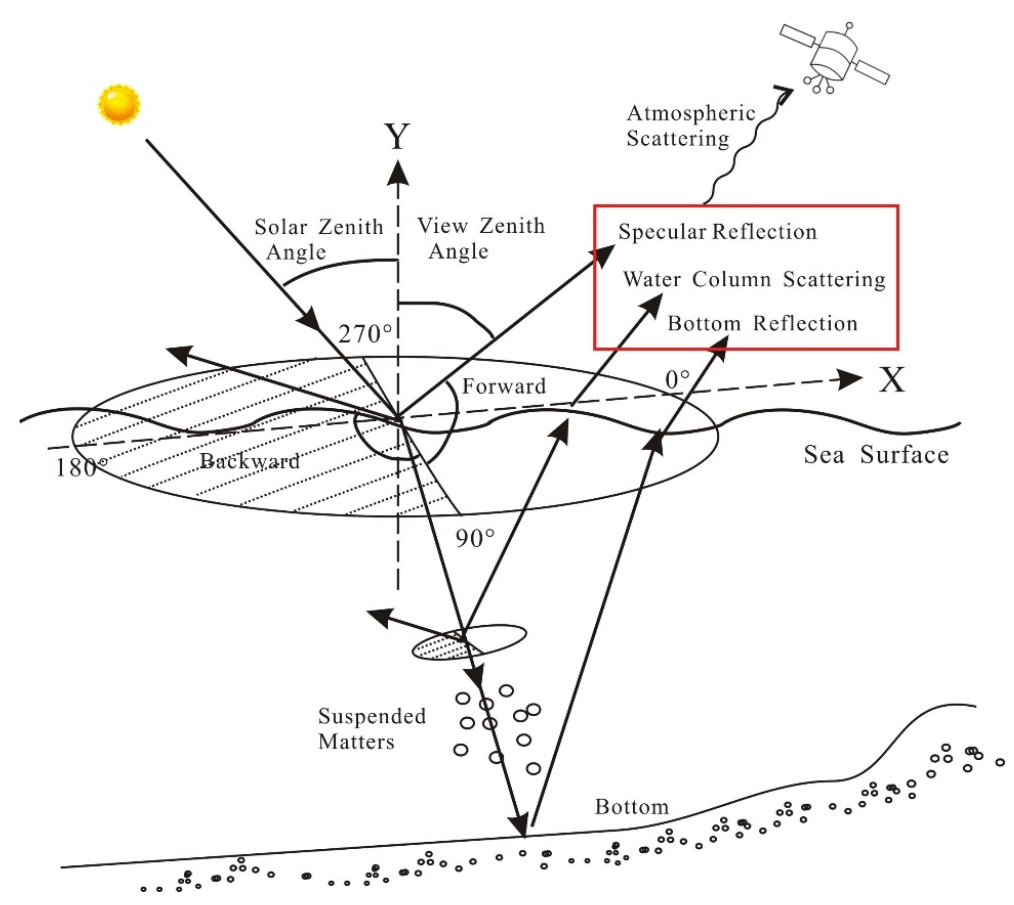

Figure 3. The reflectance just above the water surface $\left(R_{\mathrm{ap}}\right)$ gathered by the sensor includes three parts, namely, the specular reflection $\left(R_{\mathrm{sg}}\right)$, the water column scattering $\left(R_{\mathrm{rs}}\right)$, and the bottom reflectance $\left(R_{\mathrm{bw}}\right)$.

The satellite-measured top-of-atmosphere (TOA) reflectance can be expressed as follows:

$$
\rho_{\mathrm{TOA}}(\lambda)=t_{\mathrm{gas}}(\lambda)\left(t(\lambda) \cdot \rho_{\mathrm{t}}(\lambda)+\rho_{\mathrm{r}}(\lambda)+\rho_{\mathrm{A}}(\lambda)\right)
$$

where $t_{\text {gas }}(\lambda), t(\lambda), \rho_{\mathrm{t}}(\lambda), \rho_{\mathrm{r}}(\lambda)$, and $\rho_{\mathrm{A}}(\lambda)$ are the gaseous transmittance, the total diffuse atmospheric transmission, the irradiance reflectance just above the water surface, the molecular Rayleigh scattering reflectance, and the aerosol reflectance, respectively. The term $\rho_{t}(\lambda)$ can be calculated by the fast line of sight atmospheric analysis of spectral hypercube (FLAASH) module to eliminate the effect of 
the atmosphere. According to $R_{\mathrm{rs}}(\lambda)=\rho_{\mathrm{t}}(\lambda) / \pi$, the general model of $R_{\mathrm{rs}}$ above the water surface is as follows:

$$
R_{\mathrm{rs}}(I O P s, H)=R_{\mathrm{ap}}\left(S G R \text {, wind, IOPs, } H, R_{\mathrm{b}}\right)-R_{\mathrm{sg}}(S G R \text {, wind })-R_{\mathrm{bw}}\left(I O P s, H, R_{\mathrm{b}}\right)
$$

where $H, S G R$, winds, and $R_{\mathrm{b}}$ represent the water depth, the sun-satellite geometric relationship, the wind (i.e., speed and aspect), and the bottom reflectance, respectively. The symbols used in this paper are shown in Table 2.

Table 2. The symbols and abbreviations for the parameters used in this paper.

\begin{tabular}{|c|c|c|}
\hline Symbols and Abbreviations & Description & Units \\
\hline$a_{\mathrm{w}}$ & Absorption coefficient of pure water & $\mathrm{m}^{-1}$ \\
\hline$a_{\text {phy }}$ & Absorption coefficient of algal pigments & $\mathrm{m}^{-1}$ \\
\hline$a_{\mathrm{NAP}}$ & Absorption coefficient of non-algal pigments & $\mathrm{m}^{-1}$ \\
\hline$a_{\mathrm{CDOM}}$ & Absorption coefficient of CDOM & $\mathrm{m}^{-1}$ \\
\hline$a$ & Absorption coefficient of the total $\left(=a_{\mathrm{w}}+a_{\mathrm{phy}}+a_{\mathrm{NAP}}+a_{\mathrm{CDOM}}\right)$ & $\mathrm{m}^{-1}$ \\
\hline$b$ & Scattering coefficients & $\mathrm{m}^{-1}$ \\
\hline$B$ & Backscattering ratio & \\
\hline$b_{\mathrm{b}}$ & Backscattering coefficients & $m^{-1}$ \\
\hline Chl-a & Chlorophyll-a concentration & $\mathrm{ug} / \mathrm{L}$ \\
\hline$\beta(\psi, \lambda)$ & Volume scattering function (VSF) & \\
\hline$f / Q$ & Water column bidirectional factor & $\mathrm{sr}^{-1}$ \\
\hline$D$ & Bottom slope & deg \\
\hline$D^{\prime}$ & Bottom aspect & deg \\
\hline$H$ & Water depth & $\mathrm{m}$ \\
\hline$t_{\text {gas }}(\lambda)$ & Gaseous transmittance & $\mathrm{m}^{-1}$ \\
\hline$t(\lambda)$ & Total diffuse atmospheric transmission & $\mathrm{m}^{-1}$ \\
\hline$\rho_{\mathrm{t}}(\lambda)$ & Irradiance reflectance just above the water surface & \\
\hline$\rho_{\mathrm{A}}(\lambda)$ & Aerosol reflectance & \\
\hline$\rho_{\mathrm{r}}(\lambda)$ & Molecular Rayleigh scattering reflectance & \\
\hline$R_{\mathrm{rs}}$ & Remote sensing reflectance & $\mathrm{sr}^{-1}$ \\
\hline$R_{\mathrm{ap}}$ & Apparent remote sensing reflectance & $\mathrm{sr}^{-1}$ \\
\hline$R_{\mathrm{sg}}$ & Surface specular reflectance & $\mathrm{sr}^{-1}$ \\
\hline$R_{\mathrm{cW}}$ & Remote sensing reflectance from water-column scattering & $\mathrm{sr}^{-1}$ \\
\hline$R_{\mathrm{bw}}$ & Remote sensing reflectance from bottom reflectance & $\mathrm{sr}^{-1}$ \\
\hline$\theta_{0}$ & Solar zenith angle above water surface & deg \\
\hline$\theta$ & View angle above the water surface & deg \\
\hline$\theta_{0}^{\prime}$ & Subsurface solar zenith angle & deg \\
\hline$\theta^{\prime}$ & Subsurface view zenith angle & deg \\
\hline$\theta_{\mathrm{n}}$ & Water surface slope gradient & deg \\
\hline$\mu_{0}$ & Cosine of $\theta_{0}$ & \\
\hline$\mu$ & Cosine of $\theta$ & \\
\hline$\mu_{\mathrm{n}}$ & Cosine of $\theta_{\mathrm{n}}$ & \\
\hline$t_{\mathrm{u}}$ & Water-air transmittance & $\mathrm{sr}^{-1}$ \\
\hline$t_{\mathrm{d}}$ & Air-water transmittance & $\mathrm{sr}^{-1}$ \\
\hline$L$ & Optical path-elongation factor & $\mathrm{m}^{-1}$ \\
\hline$k$ & Beam attenuation coefficient $\left(=a+b_{\mathrm{b}}\right)$ & $\mathrm{m}^{-1}$ \\
\hline$\varphi$ & Relative azimuth angle & de \\
\hline$\Theta$ & Sun-satellite relative phase angle & deg \\
\hline$\sigma_{\mathrm{u}}$ & Mean square slope in an upwind direction & deg \\
\hline$\sigma_{\mathrm{c}}$ & Mean square slop in the crosswind direction & deg \\
\hline$\lambda$ & Wavelength & $\mathrm{nm}$ \\
\hline$W$ & Wind speed & $\mathrm{m} / \mathrm{s}$ \\
\hline$\Delta \varphi$ & Wind direction & deg \\
\hline$n$ & Water refractive index $(\approx 1.34$ in seawater $)$ & \\
\hline SYB & Sanya Bay & \\
\hline CDOM & Coloured dissolved organic matter & $\mathrm{m}^{-1}$ \\
\hline
\end{tabular}


Table 2. Cont.

\begin{tabular}{|c|c|c|}
\hline Symbols and Abbreviations & Description & Units \\
\hline Chl-a & Chlorophyll-a & \\
\hline CZCS & Coastal zone color scanner & \\
\hline IOPs & Inherent optical properties & \\
\hline MODIS & Moderate resolution imaging spectroradiometer & \\
\hline $2 \mathrm{Br}$ & Two-band-ratio & \\
\hline BGr & Blue-green band-ratio & \\
\hline DCI & Difference Chl-a index & \\
\hline NAP & Suspended mineral particle & $\mathrm{mg} / \mathrm{L}$ \\
\hline NIR & Near-infrared & \\
\hline $\mathrm{NRr}$ & NIR-red band-ratio & \\
\hline RGr & Red-green band-ratio & \\
\hline RSRF & Relative spectral response function & \\
\hline RTM & Radiative transfer model & \\
\hline SeaWiFS & Sea-viewing wide field of view sensor & \\
\hline SAA & Solar azimuth angle & $\operatorname{deg}$ \\
\hline SGR & Sun-satellite geometric relationship & deg \\
\hline SZA & Solar zenith angle & $\operatorname{deg}$ \\
\hline VZA & View zenith angle & $\operatorname{deg}$ \\
\hline VAA & View azimuth angle & deg \\
\hline
\end{tabular}

\subsection{Sun Glint Effect}

The view zenith angle and the view azimuth angle of traditional ocean color satellites (e.g., CZCS, MODIS, and SeaWiFS) are designed to avoid the sun glint. For land observation sensors (e.g., SPOT6, Landsat8, Aster, and GaoFen2), the acquired images may be located in sun glint areas, and so $R_{\mathrm{sg}}$ needs to be removed.

The water column has strong absorption in the NIR band of SPOT6 (i.e., $825 \mathrm{~nm}$ ); therefore, the approach of wiping off the sun glint with the NIR band has been used in remote sensing reflectance retrieval of oceanic waters [30]. However, this simple method is not available for coastal waters with high concentrations of suspended matter. Thus, we chose the physical Cox-Munk anisotropy model $[25,26]$ to calculate the sun glint of SPOT6.

The Cox-Munk model is the most classical model for simulating sun glint, and the anisotropic form of the Cox-Munk model is still the most widely used method based on the research of Zhang [27]. Sun glint may exist in the image of satellites in large view zenith angle (VZA) [28], but the sun glint pollution on the image of land observation satellites is easily ignored because there are no obvious sun glint distribution features when the view angle of each pixel in an image changes little [49].

\subsection{Water-Leaving Reflectance Contributed by Bottom Reflectance $\left(R_{b w}\right)$}

For optically shallow waters, the effect of $R_{\mathrm{bw}}$ is a non-negligible factor. $R_{\mathrm{bw}}$ is a function that depends on the bottom reflectance $\left(R_{\mathrm{b}}\right)$, the diffuse attenuation coefficient, and the water depth. According to the RTM [32], $R_{\mathrm{bw}}$ is written as follows:

$$
R_{\mathrm{bw}}=\frac{t_{\mathrm{u}} \cdot t_{\mathrm{d}}}{n^{2}} \cdot R_{\mathrm{b}} \cdot \mathrm{e}^{-\left(k_{\mathrm{u}}+k_{\mathrm{d}}\right) H}
$$

where $t_{\mathrm{u}}, t_{\mathrm{d}}, n, k_{\mathrm{u}}, k_{\mathrm{d}}$, and $H$ are the water-air transmittance, the air-water transmittance, the refractive index, the upwelling diffuse attenuation coefficient for the bottom, the downwelling diffuse attenuation coefficient for the bottom, and the water depth, respectively. Diffuse attenuation coefficients $\left(k_{\mathrm{u}}\right.$ and $k_{\mathrm{d}}$ ) depend on the SGR, a, and $b_{\mathrm{b}}$, and can be simulated by HydroLight [35] (described in Appendix A). The $R_{\mathrm{b}}$ depends on the SGR underwater surface and bottom albedo, and can be calculated by an empirical bottom bidirectional reflectance distribution fucntion (BRDF) model derived from datasets of measured bottom remote sensing reflectance [49]:

$$
R_{\mathrm{b}}\left(\theta_{0}^{\mathrm{s}}, \varphi^{\mathrm{s}}, r_{\mathrm{b}}\right)=x_{1}+x_{2} \cdot \theta_{0}^{\mathrm{s}}+\left(x_{3}+x_{4} \cdot \theta_{0}^{\mathrm{s}}\right) \cdot \exp \left(-\left(x_{5}+x_{6} \cdot \theta_{0}^{\mathrm{s}}\right) \cdot \varphi^{\mathrm{s}}\right) \cdot r_{\mathrm{b}}
$$


where the parameters $\theta_{0}^{\mathrm{s}}, \varphi^{\mathrm{s}}$, and $r_{\mathrm{b}}$ represent the incident angle at the slope, the relative azimuth angle at the slope, and the bottom albedo, respectively. The empirical parameters, $x_{\mathrm{i}}$, are based on six types of bottoms, and the parameters of grapestone sand (similar to the bottom type in Sanya) were adopted. The $x_{1-6}$ were $-0.341,0.00594,-0.853,0.0436,0.00884$, and 0.000696 , respectively. The parameter of $\theta_{0}^{\mathrm{s}}$ is the function of the bottom terrain and the SGR underwater surface:

$$
\theta_{0}^{\mathrm{s}}=\frac{1}{2} \arccos \left(\cos \theta_{0}^{\mathrm{w}} \cos \theta^{\mathrm{w}}+\sin \theta_{0}^{\mathrm{w}} \sin \theta^{\mathrm{w}} \cos \left(\varphi^{\mathrm{s}}\right)\right)-D
$$

where $\theta_{0}^{\mathrm{w}}, \theta^{\mathrm{w}}$, and $D$ represent the incident angle underwater subsurface, the view angle underwater surface, and the bottom slope, respectively; the parameter $\varphi^{\mathrm{s}}=\varphi-D^{\prime}$, where $D^{\prime}$ is the bottom aspect.

\section{Chl-a Concentration Retrieval Algorithm}

The effects of sun glint, bottom reflectance, and NAP have a great impact on Chl-a concentration retrieval in optically shallow zones of coastal waters using broad-band satellites. In this paper, a semi-empirical algorithm is proposed to reduce the effects of these limitations, and SPOT6 data serve as the reflectance data. The general flow chart of the Chl-a concentration retrieval process is shown in Figure 4.

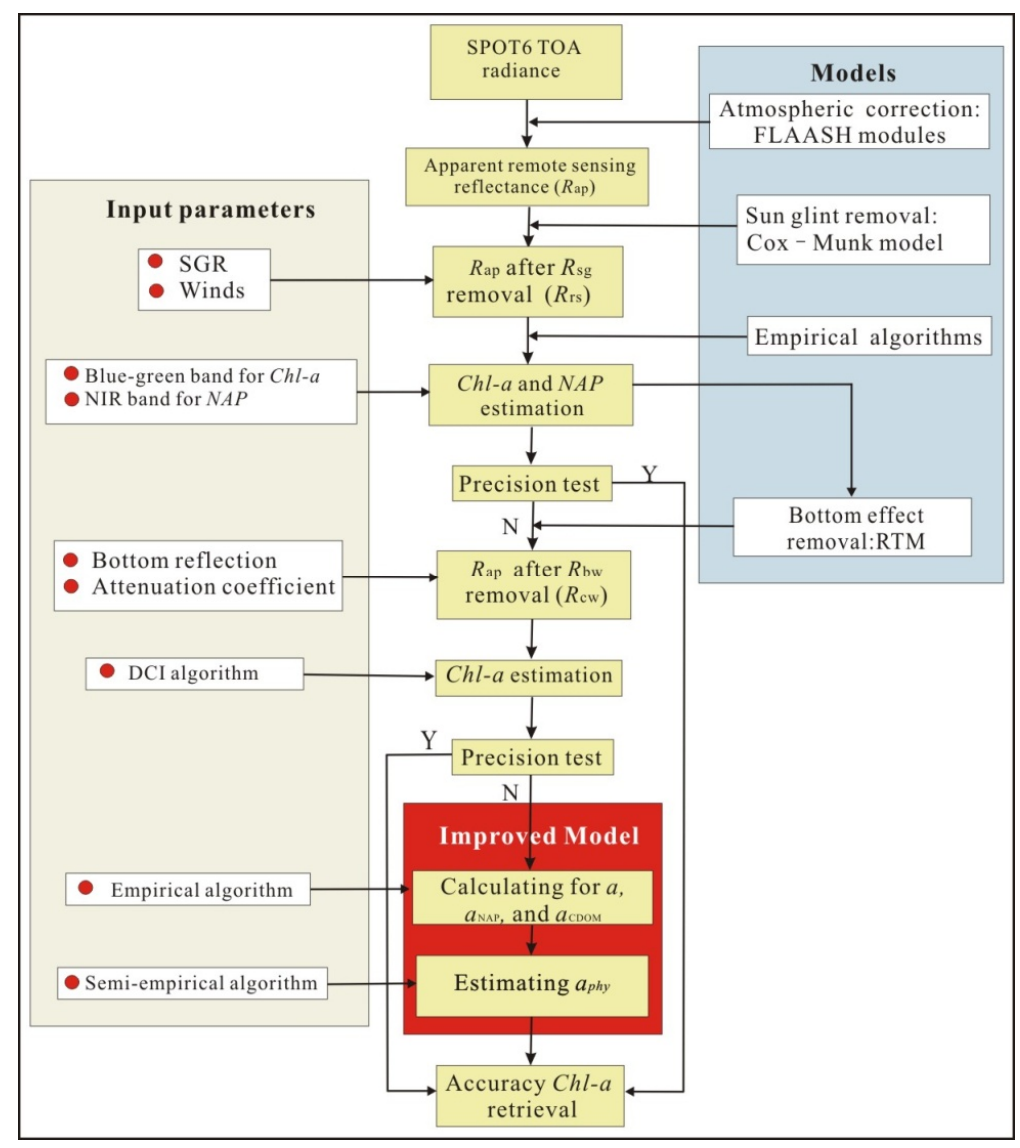

Figure 4. Flow chart of the retrieval algorithm. Chl-a, chlorophyll-a; FLAASH, fast line of sight atmospheric analysis of spectral hypercube; NAP, non-algal particle; NIR, near-infrared; RTM, radiative transfer model; SGR, sun-satellite geometric relationship; TOA, top-of-atmosphere; DCI, difference Chl-a index.

\subsection{Review of the Chl-a Retrieval Algorithm}

According to the IOPs in different types of waters, there are mainly three kinds of empirical or semi-empirical algorithms for Chl-a retrieval: two-band ratio algorithms (e.g., BGr and red-green band 
ratio, RGr), spectral band difference algorithms (e.g., Fluorescence Line Height (FLH), color index $(\mathrm{CI})$, and maximum chlorophyll index (MCI)). The selection of bands and methods for Chl-a retrieval needs to consider the positions of the Chl-a absorption peak and the interferences from CDOM and NAP. The absorption peaks of Chl-a are mainly located near $440 \mathrm{~nm}, 660 \mathrm{~nm}$, and $705 \mathrm{~nm}$, and the absorption peak of Chl-b (near $490 \mathrm{~nm}$ ) has been used to replace $440 \mathrm{~nm}$ to reduce the effect of CDOM. The excellent correlation between Chl-a and chlorophyll-b (Chl-b) ensures the feasibility of this replacement. The algorithms based on an absorption peak at $705 \mathrm{~nm}$ are proposed to reduce the effect of NAP.

The principle of the QAA algorithm is to obtain the Chl-a absorption coefficient by the IOPs calculated by the reflectance, and the principle of the empirical or semi-algorithms are based on the spectral features of waters with different Chl-a concentrations. On the basis of the band settings of SPOT6 data (red band: 450-520 nm; green band: 530-590 nm), the algorithms of BGr, CI, and RGr were adopted to estimate the concentration of $\mathrm{Chl}-\mathrm{a}$ in this paper. For reducing the effect of sun glint and bottom reflectance, we also tried another form of the blue-green band algorithm to retrieve the Chl-a concentration, and this algorithm is called the difference Chl-a index (DCI). The DCI algorithm is an empirical algorithm based on the difference of reflectance between blue band and green band. The algorithms of BGr, CI, and DCI are based on an absorption peak at blue band and RGr is based on an absorption peak at red band. The common Chl-a retrieval algorithms are shown in Table 3. For reducing the effect of NAP on empirical algorithms, we propose an improved semi-empirical algorithm for Chl-a concentration algorithm and describe in the next section.

Table 3. The common algorithms and spectral bands (in nanometers) for Chl-a concentration retrieval.

\begin{tabular}{ccccc}
\hline Algorithm & Sensor & Band & Water Type & Reference \\
\hline BGr & OLI & 483,562 & Eutrophic inland & {$[23,24]$} \\
RGr & Sentinel-2 & 665,560 & Eutrophic inland & {$[13]$} \\
OC3M & MODIS & $443,488,555$ & Case-2 coastal & {$[12]$} \\
QAA & SeaWiFS & $443,490,550,667$ & Case-2 coastal & {$[10,11]$} \\
FLH & MODIS & $667,678,746$ & Eutrophic coastal & {$[50]$} \\
CI & MERIS & $443,555,670$ & Oligotrophic & {$[51]$} \\
MCI & MERIS & $681,709,753$ & Eutrophic coastal & {$[52,53]$} \\
\hline
\end{tabular}

\subsection{Improved Chl-a Concentration Algorithm}

Chl-a concentration retrieval using remote sensing methods is based on the relationship between IOPs and the remote sensing reflectance. For optically deep waters, $R_{\mathrm{rs}}$ is the function of IOPs and the SGR $[54,55]$. However, for optically shallow waters, $R_{\mathrm{rs}}$ is also a function of water depth. On the basis of the RTM, the $R_{\text {rs }}$ can be written as follows [32,35]:

$$
R_{\mathrm{rs}}(I O P s, f, Q)=\frac{t_{\mathrm{u}} \cdot t_{\mathrm{d}}}{n^{2}} \cdot \frac{f}{Q} \cdot r_{\mathrm{rs}}\left(a, b_{\mathrm{b}}\right) \cdot\left[1-\exp \left(-\left(k_{\mathrm{u}}+k_{\mathrm{d}}\right) \cdot H\right)\right]
$$

where $r_{\mathrm{rs}}$ and the parameters $r_{\mathrm{rs}}, f / Q, a$, and $b_{\mathrm{b}}$ are the subsurface remote sensing reflectance, the bidirectional factor for reflectance just above the water surface, the total absorption coefficient, and the total backscattering coefficient, respectively. The polynomial, $\left[1-\exp \left(-\left(k_{\mathbf{u}}+k_{\mathrm{d}}\right) \cdot H\right)\right]$ in Equation (5), is the effect of the water depth and needs to be removed. The parameter $f / Q$ is the function of the SGR, the winds, and the water constituents, and it can be calculated by the experimental function simulated by the HydroLight dataset [35]. In the absence of the value of $f / Q$, the subsurface remote sensing reflectance $\left(r_{\mathrm{rs}}\right)$ can be calculated by the QAA when the solar zenith angle (SZA) is larger than $20^{\circ}$ [15]:

$$
r_{\mathrm{rs}}=\frac{R_{\mathrm{rs}}(\lambda)}{0.52+1.7 R_{\mathrm{rs}}(\lambda)}
$$


The relationship between $r_{\mathrm{rs}}$ and the ratio of the total backscattering coefficient to the total absorption coefficient $u(\lambda)$ can be written as follows:

$$
u(\lambda)=\frac{-\mathrm{g}_{0}+\sqrt{\left(\mathrm{g}_{0}\right)^{2}+4 \mathrm{~g}_{1} \cdot r_{\mathrm{rs}}(\lambda)}}{2 \mathrm{~g}_{1}}
$$

The ratio of $u\left(\lambda_{1}\right)$ to $u\left(\lambda_{2}\right),\left(u_{\text {ratio }}\right)$ can be used to retrieve the concentration of Chl-a instead of the ratio of $r_{\mathrm{rs}}\left(\lambda_{1}\right)$ to $r_{\mathrm{rs}}\left(\lambda_{2}\right)$. According to the relationship between IOPs and $u(\lambda), u(\lambda)=b_{\mathrm{b}}(\lambda) /\left(a(\lambda)+b_{\mathrm{b}}(\lambda)\right)$, the $u_{\text {ratio }}$ can be written as follows:

$$
u_{\text {ratio }}=\frac{u\left(\lambda_{1}\right)}{u\left(\lambda_{2}\right)}=\frac{b_{b}\left(\lambda_{1}\right)}{b_{b}\left(\lambda_{2}\right)} \cdot \frac{a\left(\lambda_{2}\right)}{a\left(\lambda_{1}\right)}
$$

The main constituents affecting IOPs are the water molecules, Chl-a, NAP, and CDOM, and the parameters of $a$ and $b_{\mathrm{b}}$ can be written as follows [56,57]:

$$
\begin{gathered}
a=a_{\mathrm{w}}+a_{\mathrm{phy}}^{*} \cdot \mathrm{Chl}-\mathrm{a}+a_{\mathrm{NAP}}^{*} \cdot \mathrm{NAP}+a_{\mathrm{CDOM}} \\
b=b_{\mathrm{bw}}+b_{\mathrm{bphy}}^{*} \cdot \mathrm{Chl}-\mathrm{a}+b_{\mathrm{bNAP}}^{*} \cdot \mathrm{NAP}
\end{gathered}
$$

The pure seawater backscattering $\left(b_{\mathrm{bw}}\right)$ is constant and much less than the particle backscattering $\left(b_{\mathrm{bp}}=b_{\mathrm{bNAP}}+b_{\mathrm{bphy}}\right)[58,59]$, and the particle backscattering coefficient $\left(b_{\mathrm{p}}\right)$ changes little in the visible and NIR bands [35,57,60-62]. To reduce the model complexity, $u_{\text {ratio }}$ can be converted to the following [8]:

$$
u_{\text {ratio }} \approx \frac{a\left(\lambda_{2}\right)}{a\left(\lambda_{1}\right)}
$$

To reduce the effect of $a_{\mathrm{NAP}}, a_{\mathrm{w}}$, and $a_{\mathrm{cdom}}$, Equations (8) and (10b) can be merged and written as follows:

$$
a_{\text {phy }}\left(\lambda_{2}\right)=\frac{u\left(\lambda_{1}\right)}{u\left(\lambda_{2}\right)} \cdot a\left(\lambda_{1}\right)-\left[a_{\mathrm{w}}\left(\lambda_{2}\right)+a_{\mathrm{NAP}}\left(\lambda_{2}\right)+a_{\mathrm{CDOM}}\left(\lambda_{2}\right)\right]
$$

For oceanic waters or phytoplankton-dominated waters, $a_{\text {phy }}$ is approximately equal to the particle absorption coefficient $\left(a_{\mathrm{p}}\right)$. For coastal waters of SYB in winter, $a_{\mathrm{NAP}}$ is an important parameter, whose proportion is over $80 \%$ in the $a_{\mathrm{p}}$ (as shown in Table 1). We thus propose the semi-empirical algorithm to retrieve the concentration of Chl-a by absorption of $a_{\text {phy }}$. The parameters of $a_{\mathrm{W}}, a_{\mathrm{NAP}}$, $a_{\mathrm{CDOM}}$, and $a$ are unknown. Therefore, $a_{\mathrm{w}}$ was adopted by the measured data from Pope and Fry [63]; $a_{\text {NAP }}$ was calculated by the semi-analytical model proposed by Tassan, as shown in Appendix A.3; and $a_{\mathrm{CDOM}}$ is calculated by an empirical algorithm as shown in Appendix A.4. The Chl-a concentration was estimated by the empirical algorithm (e.g., DCI, BGr, and RGr). The parameter $a(\lambda)$ is the sum of $a_{\mathrm{W}}, a_{\mathrm{NAP}}, a_{\mathrm{CDOM}}$, and $a_{\mathrm{phy}}$ (as shown in Equation (10a)), and the semi-empirical algorithm uses the parameters of $a, a_{\mathrm{NAP}}, a_{\mathrm{CDOM}}$, and $a_{\mathrm{w}}$ to calculate $a_{\mathrm{phy}}$ (as shown in Equations (11) and (12)).

\section{Results}

\subsection{SPOT6 Data Atmospheric Correction}

The atmospheric correction of remote sensing data is the first step in Chl-a retrieval and may remove over $70-90 \%$ of the signal measured by the sensor in the visible bands $[27,28,64]$. The fast line of sight atmospheric analysis of spectral hypercube (FLAASH) module is a widely used atmospheric correction module for multi-band remote sensing data and is based on MODTRAN4 (moderate spectral resolution atmospheric transmittance algorithm and computer model) [64-66]. FLAASH has been successfully used for the atmospheric correction of SPOT6 image data $[67,68]$, and the input parameters are shown in Table 4. The meteorological data were retrieved from the National Meteorological 
Information Center: http://data.cma.cn/data/cdcindex/cid/6b2344874db4bbaf.html. As we did not have in situ reflectance measurements above the water surface in the SYB, we collected the reflectance of the wet and dry sand for calibration of the atmospheric correction (as shown in Figure 5). We also applied the FLAASH module to the Landsat8 OLI (imaging time: 15 June 2013) and used the in situ reflectance data from coastal waters in Qinghuangdao (sampling in $119.80^{\circ} \mathrm{E}, 39.95^{\circ} \mathrm{N}$ on 15 June 2013) to verify the calibration of the atmospheric correction (as shown in Figure 6). The reflectance data were measured by the FieldSpec 3 Spectroradiometer (America, ASD Company, Alpharetta, GA, USA).

Table 4. Input parameters in fast line of sight atmospheric analysis of spectral hypercube (FLAASH).

\begin{tabular}{cccc}
\hline Sensor Type & SPOT 6 & Atmospheric Model & Tropical \\
\hline Sensor altitude & $695 \mathrm{~km}$ & Aerosol model & Maritime \\
Ground elevation & $0 \mathrm{~m}$ & Initial visibility & $30 \mathrm{~km}$ \\
Flight data & 21 January 2013 & View zenith angle & $22^{\circ}$ \\
Flight time & $10: 58$ & View azimuth angle & $135^{\circ}$ \\
\hline
\end{tabular}

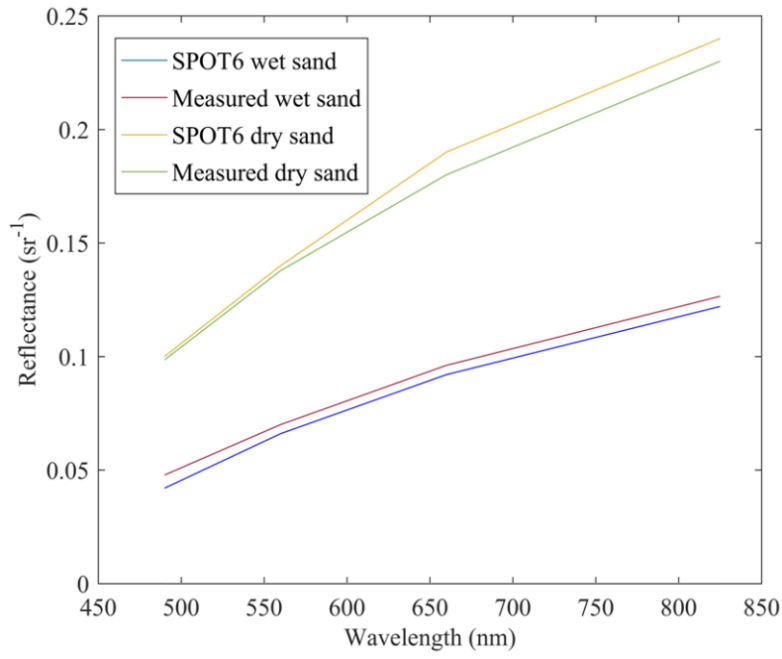

Figure 5. The comparison of the sand remote sensing reflectance of SPOT6 data and the measured data.

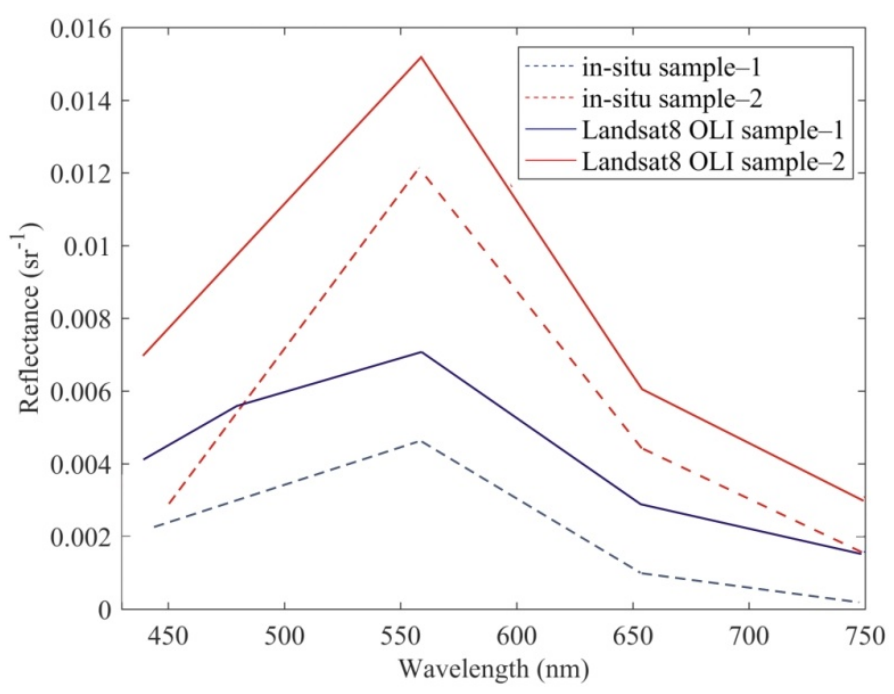

Figure 6. The comparison of reflectance from Landsat8 OLI and in situ data resampled by relative spectral respond function of Landsat8 OLI. The water constituents of sample 1 are as follows: Chl-a $=1.6 \mathrm{ug} / \mathrm{L}$ and $\mathrm{NAP}=6.6 \mathrm{mg} / \mathrm{L}$; the water constituents of sample 2 are as follows: $\mathrm{Chl}-\mathrm{a}=16 \mathrm{ug} / \mathrm{L}$ and NAP $=16.8 \mathrm{mg} / \mathrm{L}$. 


\subsection{Parameter $u(\lambda)$ Correction}

The $a_{\text {phy }}$ was calculated by $u(\lambda)$, as shown in Equation (12). Therefore, $u(\lambda)$ was calculated by $R_{\text {ap }}$, $R_{\mathrm{rs}}$, and $r_{\mathrm{rs}}$ to show the effects of sun-glint and bottom. In Figure 7 , the green circles, the red diamonds, and the blue rectangles represent the $u(\lambda)$ calculated by $R_{\mathrm{ap}}, R_{\mathrm{rs}}$, and $r_{\mathrm{rs}}$, respectively. The effects of sun glint (as shown in green circles) and bottom reflectance (as shown in blue rectangles) increase the value of $u(\lambda)$. The effect of sun glint is larger than the bottom reflectance, and the error caused by sun glint may be over $20 \%$. After model correction, the $u(\lambda)$ calculated by the $r_{\text {rs }}$ of the SPOT6 data and those calculated by the in situ data have good agreement.
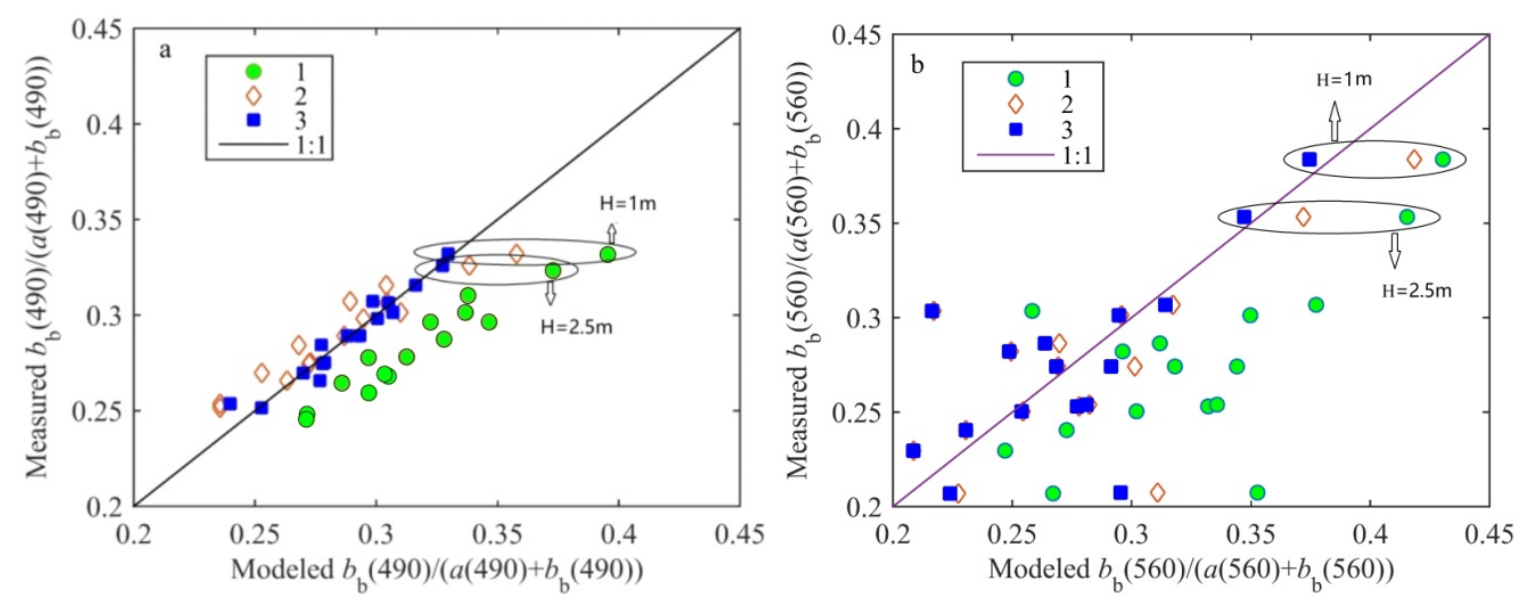

Figure 7. Comparison between $u(\lambda)$ calculated by in situ data and those calculated by remote sensing reflectance data ( 1 , calculated by $R_{\mathrm{ap}} ; 2$, calculated by $R_{\mathrm{rs}} ; 3$, calculated by $r_{\mathrm{rs}}$ ) for (a) the waveband at $490 \mathrm{~nm}$ and (b) the waveband at $560 \mathrm{~nm}$.

\subsection{Comparison of the Different Algorithms}

For SPOT6 data, there is no available analytical or semi-analytical algorithm, so we tried different empirical algorithms to retrieve the concentration of Chl-a. According to the absorption characteristics of Chl-a and the relative response function (RSRF) of SPOT6, the BGr, RGr, CI, and DCI algorithms $[8,10,12,13,51]$ were applied to the remote sensing reflectance processed by atmospheric correction using SPOT6 data. The algorithm correlation coefficients are shown in Figure 8.

Although the correlation between RGr and Chl-a concentration is better than the other three algorithms, $\mathrm{RGr}$ and Chl-a concentration should be positively correlated rather than negatively correlated based on the absorption characteristics of Chl-a. NAP and RGr are positively correlated, and the NAP signal masks the Chl-a concentration signal in waters with a high concentration of NAP using the RGr algorithm. Thus, we applied the BGr and DCI on $R_{\mathrm{rs}}$ (i.e., $R_{\mathrm{ap}}$ without the effect of sun glint) to retrieve the concentration of Chl-a (Figure 9).

In the same image, the sun glint decreases as the wavelength gets longer owing to the variation of the water refractive index, but the sun glint changes less than $5 \%$ in the visible bands [30]. If the sun glint is small, the sun glint effects on BGr or DCI can be ignored, and the DCI has stronger resistance to sun glint (as shown in Figure 8a,d and Figure 9). The value of the SPOT6 image sun glint calculated by the Cox-Munk model is 0.01 in the blue band; thus, the effect of the sun glint is very small for the DCI algorithm.

The effect of the bottom on Chl-a concentration retrieval in optically shallow waters depends on the bottom reflectance and the attenuation coefficient. The attenuation coefficients in the visible bands are less than those in the NIR bands, and the effect of $R_{\mathrm{bw}}$ on the blue and green bands needs to be considered. Better correlation coefficients were obtained by the BGr and DCI algorithms without bottom reflectance, and a relatively good correlation coefficient $\left(R^{2}=0.75\right)$ was obtained by the DCI algorithm (as shown in Figure 10). The accuracy of global Chl-a concentration retrieval based on 
the MODIS algorithm reached $\mathrm{R}^{2}=0.85$, and thus the accuracy of the DCI algorithm still needs to be improved.

For the BGr and DCI algorithms, the effect of NAP may be the most important factor for Chl-a concentration retrieval, because the absorption of NAP in the blue and green bands is much larger than the absorption of Chl-a. We applied the semi-analytical algorithm based on $a_{\text {phy }}$ (490) to reduce the effect of NAP, and the accuracy of algorithm was improved $\left(R^{2}=0.91\right.$ as shown in Figure 11). The retrieval results using $a_{\text {phy }}(660)$ inverted by the semi-analytical algorithm were not as good as those using $a_{\text {phy }}(490)$, which may be because the wavelength range of the SPOT6 red band (625-695 nm) contains not only a strong Chl-a spectral absorption, but also a weak Chl-a spectral reflection (as shown in Appendix A.1).
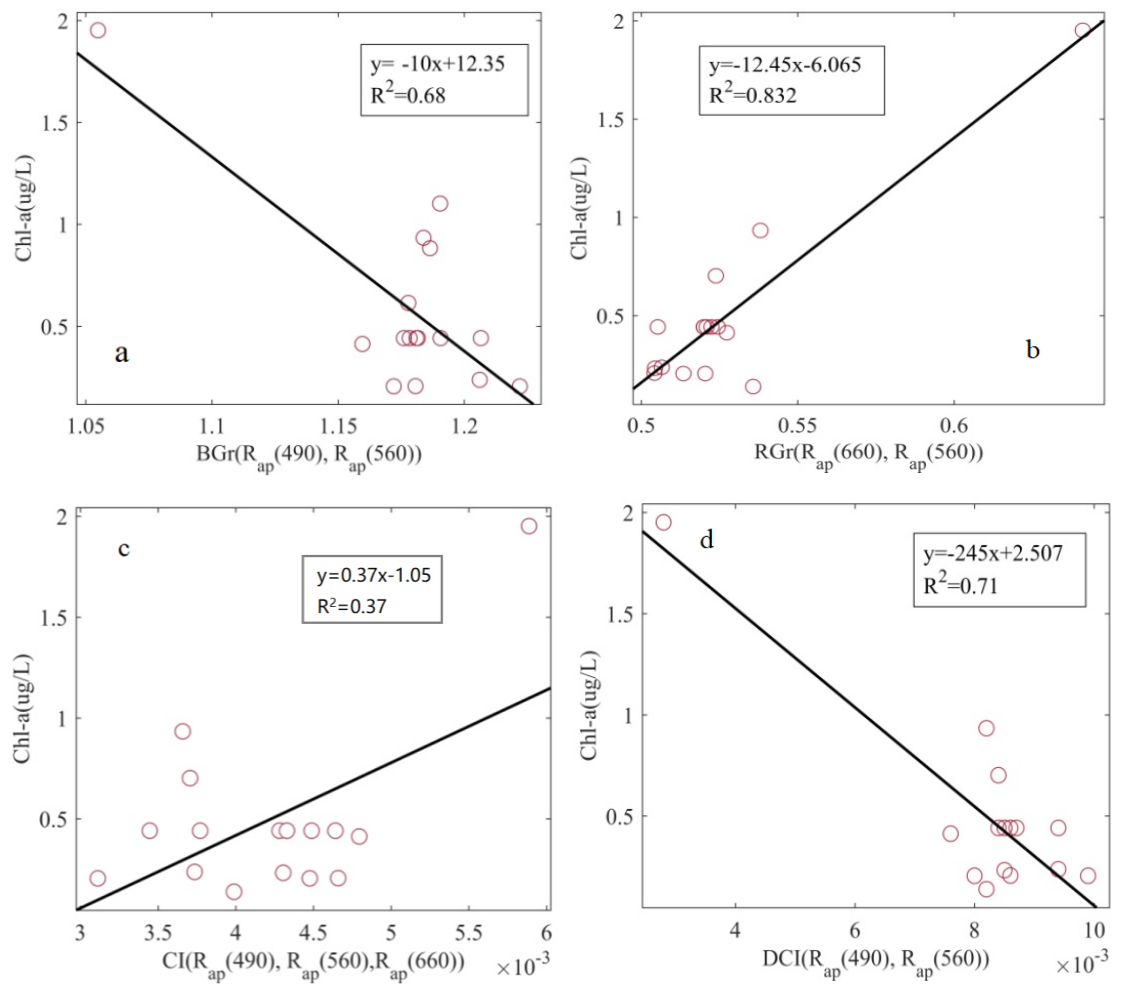

Figure 8. Scatterplots of the Chl-a concentration as a function of (a) BGr calculated by $R_{\mathrm{ap}}(490)$ and $R_{\mathrm{ap}}$ (560); (b) RGr calculated by $R_{\mathrm{ap}}(560)$ and $R_{\mathrm{ap}}(660)$; (c) color index (CI) calculated by $R_{\mathrm{ap}}(490)$, $R_{\text {ap }}$ (560), and $R_{\text {ap }}(660)$; and (d) DCI calculated by $R_{\text {ap }}(490)$ and $R_{\text {ap }}(560)$.
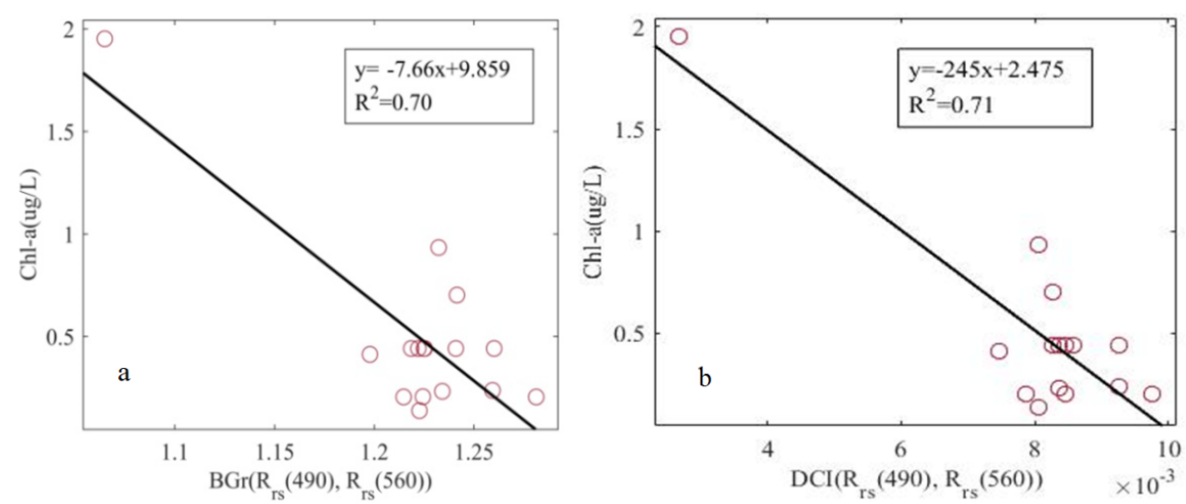

Figure 9. Scatterplots of the Chl-a concentration as a function of (a) BGr calculated by $R_{\mathrm{rs}}(490)$ and $R_{\mathrm{rs}}(560)$, and (b) DCI calculated by $R_{\mathrm{rs}}(490)$ and $R_{\mathrm{rs}}(560)$. 

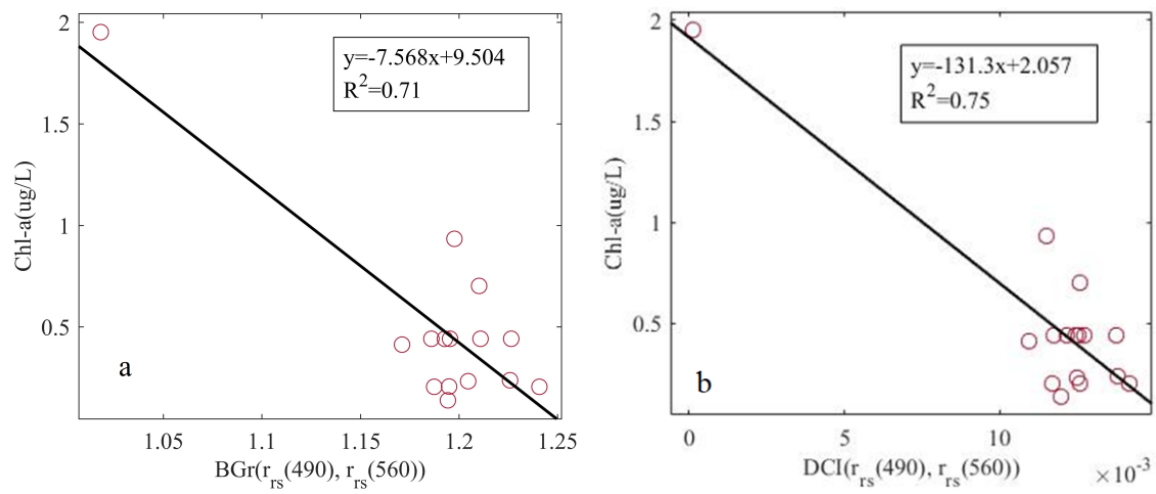

Figure 10. Scatterplots of the Chl-a concentration as a function of (a) BGr calculated by $r_{\mathrm{rs}}(490)$ and $r_{\mathrm{rs}}(560)$, and (b) DCI calculated by $r_{\mathrm{rs}}(490)$ and $r_{\mathrm{rs}}(560)$.

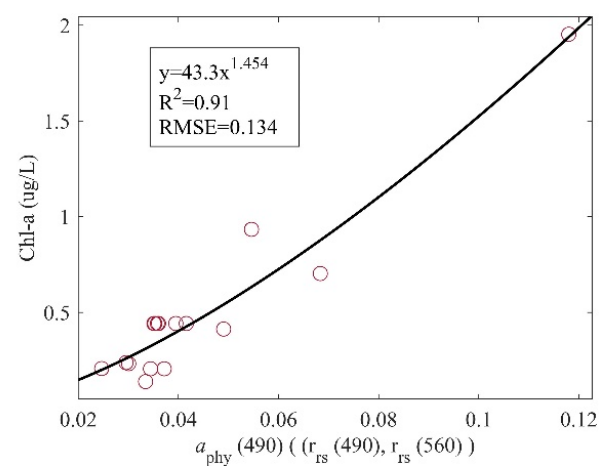

(a)

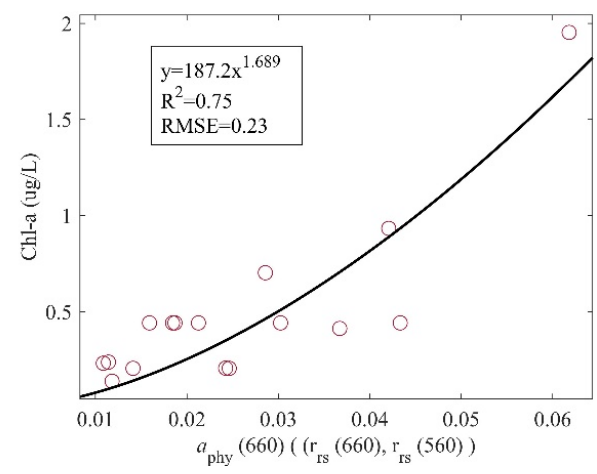

(b)

Figure 11. Scatterplots of the Chl-a concentration as a function of (a) $a_{\mathrm{phy}}$ (490) calculated by $r_{\mathrm{rs}}(490)$ and $r_{\mathrm{rs}}(560)$, and (b) $a_{\mathrm{phy}}$ (660) calculated by $r_{\mathrm{rs}}$ (560) and $r_{\mathrm{rs}}(660)$. RMSE, root mean square error.

According to the comparison of different algorithms (as shown in Figures 8-11), the algorithms based on BGr, DCI, and $a_{\text {phy }}(490)$ are available. We compared the Chl-a retrieval results by different reflectance using different algorithms to analyze the performance of the semi-empirical algorithm proposed in this paper (as shown in Figure 12). This semi-empirical algorithm can be used to reduce the effects of boundary conditions (i.e, sun glint and bottom) and NAP.

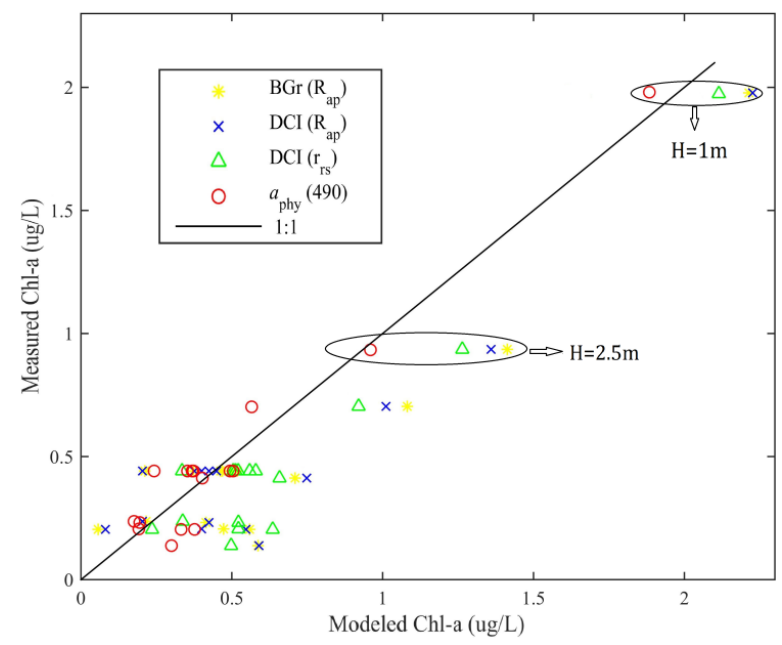

Figure 12. Comparison of the Chl-a retrieval results retrieved by BGr calculated by $R_{\mathrm{ap}}$, DCI calculated by $R_{\mathrm{ap}}$, DCI calculated by $r_{\mathrm{rs}}$, and $a_{\mathrm{phy}}(490)$. 


\subsection{Statistical Analysis}

A number of statistical methods were used in this paper to compare the different algorithms, the coefficient of determination $\left(R^{2}\right)$, the root mean square error (RMSE), the mean absolute percentage error (MAPE), and the relative error (RE).

$$
\begin{gathered}
\mathrm{R}^{2}=1-\frac{\sum\left(y_{\text {measured }}-y_{\text {modeled }}\right)^{2}}{\sum\left(y_{\text {measured }}-\overline{y_{\text {modeled }}}\right)^{2}} \\
\text { MAPE }=\frac{1}{m} \sum 100\left|\frac{y_{\text {measured }}-y_{\text {modeled }}}{y_{\text {measured }}}\right| \\
\mathrm{RMSE}=\sqrt{\frac{1}{m}\left(y_{\text {measured }}-y_{\text {modeled }}\right)^{2}} \\
\mathrm{RE}=\left|\frac{y_{\text {measured }}-y_{\text {modeled }}}{y_{\text {measured }}}\right| \times 100 \%
\end{gathered}
$$

where $m$ is the sample number, $y_{\text {measured }}$ is the observed value, $y_{\text {modeled }}$ is the predicted value, and $\overline{y_{\text {modeled }}}$ is the expectation of the observed value, where $y$ is the Chl-a concentration calculated by different algorithms using different reflectance of $R_{\mathrm{ap}}, R_{\mathrm{rs}}$, and $r_{\mathrm{rs}}$. The empirical coefficients of the

\begin{tabular}{|c|c|c|c|c|c|}
\hline Algorithm & Data & Empirical Coefficients & $\mathbf{R}^{2}$ & RMSE & MAPE \\
\hline \multirow{3}{*}{ BGr } & $R_{\mathrm{ap}}(\lambda)$ & $\begin{array}{c}y=67.85 x^{2}-163.9 x+99.31 \\
Y=-10 x+12.35\end{array}$ & $\begin{array}{l}0.72 \\
0.68\end{array}$ & $\begin{array}{l}0.2255 \\
0.2565\end{array}$ & $\begin{array}{l}41.72 \% \\
66.23 \%\end{array}$ \\
\hline & $R_{\mathrm{rs}}(\lambda)$ & $\begin{array}{c}y=42.98 x^{2}-108.9+68.18 \\
y=-7.66 x+9.859\end{array}$ & $\begin{array}{c}0.74 \\
0.7\end{array}$ & $\begin{array}{l}0.2243 \\
0.2444\end{array}$ & $\begin{array}{l}36.28 \% \\
50.46 \%\end{array}$ \\
\hline & $r_{\mathrm{rs}}(\lambda)$ & $\begin{array}{c}y=47.85 x^{2}-116.9+71.78 \\
y=-7.57 x+9.5\end{array}$ & $\begin{array}{l}0.75 \\
0.72\end{array}$ & $\begin{array}{l}0.2223 \\
0.2422\end{array}$ & $\begin{array}{l}40.93 \% \\
41.56 \%\end{array}$ \\
\hline \multirow{3}{*}{ DCI } & $R_{\mathrm{ap}}(\lambda)$ & $\begin{array}{c}y=-8901 x^{2}-1042 x+2.061 \\
y=-245 x+2.507\end{array}$ & $\begin{array}{l}0.76 \\
0.71\end{array}$ & $\begin{array}{l}0.2151 \\
0.2277\end{array}$ & $\begin{array}{l}36.09 \% \\
45.92 \%\end{array}$ \\
\hline & $R_{\mathrm{rs}}(\lambda)$ & $\begin{array}{c}y=-8901 x^{2}-1025 x+2.04 \\
Y=-245 x+2.475\end{array}$ & $\begin{array}{l}0.76 \\
0.71\end{array}$ & $\begin{array}{l}0.2151 \\
0.2277\end{array}$ & $\begin{array}{l}36.04 \% \\
45.76 \%\end{array}$ \\
\hline & $r_{\mathrm{rs}}(\lambda)$ & $\begin{array}{c}y=-4478 x^{2}-558.2 x+1.843 \\
y=-131.3 x+2.057\end{array}$ & $\begin{array}{l}0.77 \\
0.75\end{array}$ & $\begin{array}{l}0.2141 \\
0.2253\end{array}$ & $\begin{array}{l}36.15 \% \\
38.97 \%\end{array}$ \\
\hline$a_{\text {phy }}(490)$ & $r_{\mathrm{rs}}(\lambda)$ & $y=43.3 x^{1.454}$ & 0.91 & 0.11 & $21.51 \%$ \\
\hline
\end{tabular}
algorithms in this paper are shown in Table 5.

Table 5. The statistics of algorithms in this paper. RMSE, root mean square error; MAPE, mean absolute percentage error.

\subsection{Sun Glint Effect}

We used polarization coordinates to show the sun glint distribution and the radius and polar angle present the view zenith angle and relative azimuth angle (solar direction $=180^{\circ}$ ), respectively. Although the SPOT6 image is not located in the center of the sun glint (red circle represents the view direction of SPOT6, as shown in Figure 13), it is a non-negligible signal $\left(\approx 0.01 \mathrm{sr}^{-1}\right)$ because $R_{\mathrm{rs}}$ is very small. The scope of the sun glint zone expands as the wind speed increases, and the SPOT6 image will locate in the sun glint zone if the wind speed is strong enough. Figure 13 shows the sun glint distribution, and Figure 14 shows that the reflectance at $825 \mathrm{~nm}$ is close to the $R_{\mathrm{sg}}$ calculated by the Cox-Munk model when the concentration of NAP is low, which proves that the Cox-Munk model is still reliable when the image is on the edge of the sun glint area with a low value. 


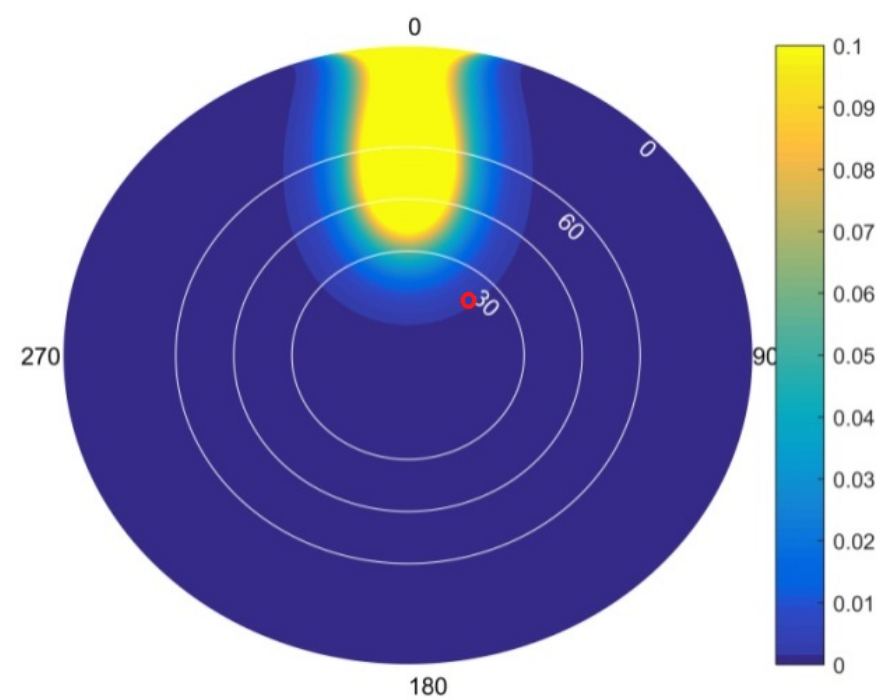

Figure 13. The sun glint distribution in terms of SGR and wind speed: the solar zenith angle (SZA), view zenith angle (VZA), view azimuth angle (VAA), wind speed, and wind direction are $49^{\circ}, 22^{\circ}$, $145^{\circ}, 5.3 \mathrm{~m} / \mathrm{s}$, and $2^{\circ}$, respectively. The red circle shows the SPOT6 view conditions acquired from the website: https://www.intelligence-airbusds.com/en/4871-ordering.

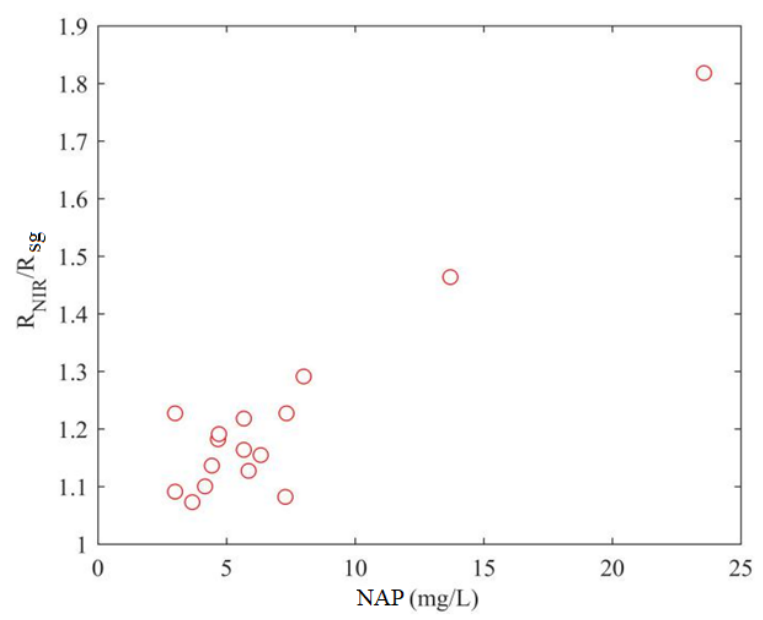

Figure 14. The ratio of reflectance at $825 \mathrm{~nm}$ to the value of the sun glint calculated by the Cox-Munk model versus NAP.

In our study, $R_{\mathrm{rs}}$ ranged from 0.03 to $0.05 \mathrm{sr}^{-1}$ in the visible bands and the proportion of $R_{\mathrm{sg}}$ in $R_{\mathrm{rs}}$ ranged from approximately $20 \%$ to $30 \%$. Hence, we simulated the sensitivity of the two-band algorithm (including BGr, RGr, and DCI) to $R_{\mathrm{sg}}$ to analyze the effect of sun glint on Chl-a concentration retrieval (Figure 15). The remote sensing reflectance $\left(R_{\mathrm{ap}}\right)$ at $490 \mathrm{~nm}$ and $560 \mathrm{~nm}$ was simulated by Equations (1) and (5), and the parameters $N A P=1 \mathrm{mg} / \mathrm{L}$ and $C h l-a=0.3-10$ were the model input parameters. In order to control the variables, the effects of bottom reflectance and NAP were not considered in this analysis. 

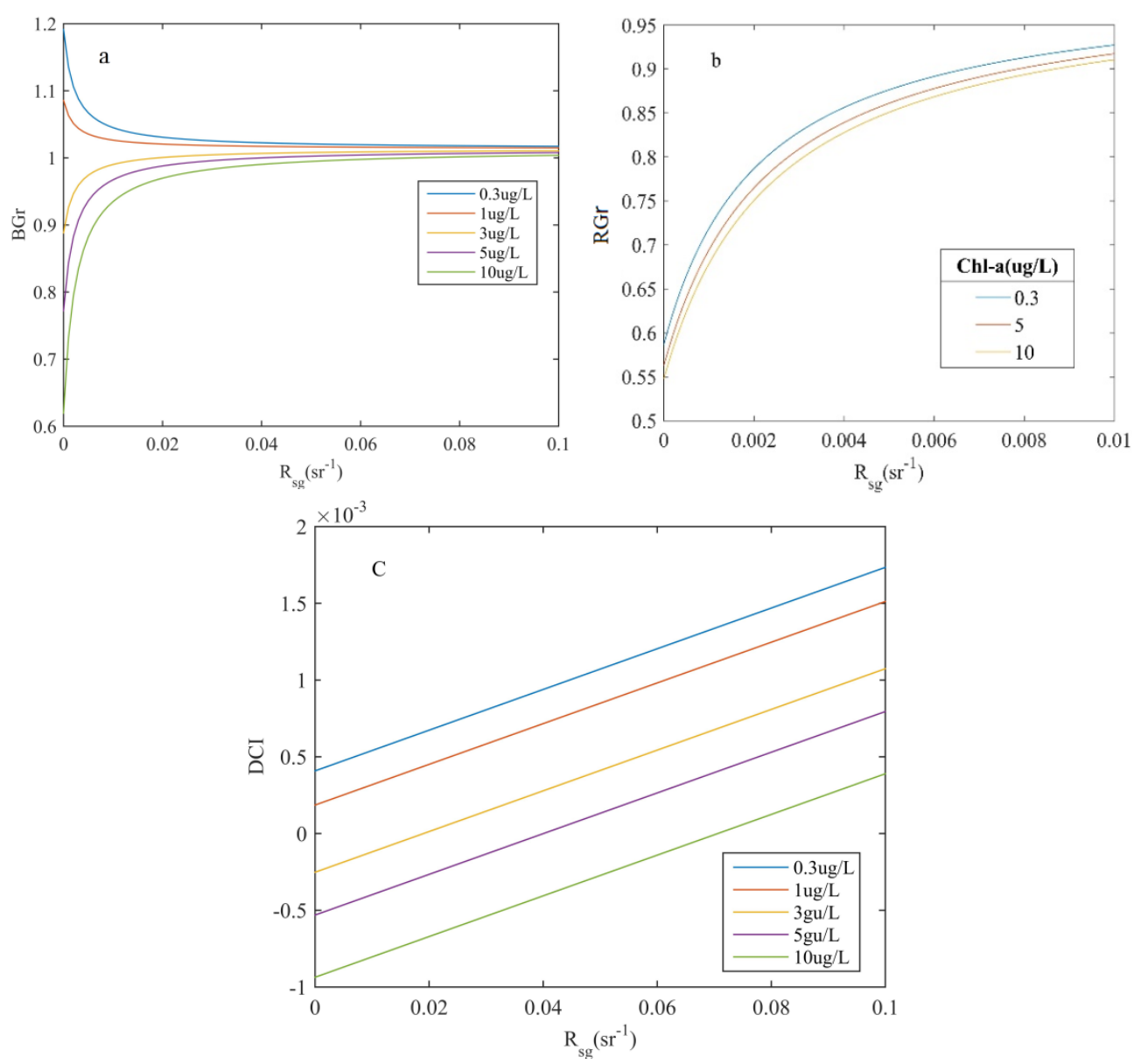

Figure 15. Remote sensing reflectance contributed by sun glint $\left(R_{\mathrm{sg}}\right)$ against the following: (a) the ratio of $R_{\mathrm{ap}}(490)$ to $R_{\mathrm{ap}}$ (560); (b) the ratio of $R_{\mathrm{ap}}$ (560) to $R_{\mathrm{ap}}(660)$; and (c) the difference between $R_{\mathrm{ap}}(490)$ and $R_{\text {ap }}(560)$.

As the value of the sun glint goes up, the ratio of the two-band reflectance approaches 1 and the variations of the two-band ratio $(2 \mathrm{Br})$ in different $\mathrm{Chl}$-a concentrations are reduced. This phenomenon reduces the sensitivity of $R_{\mathrm{sg}}$ to the variation of $\mathrm{Chl}-\mathrm{a}$ concentration and causes the $2 \mathrm{Br}$ algorithm to lose its ability to retrieve Chl- $a$. Relative to the $2 \mathrm{Br}$, the DCI has better resistance ability to sun glint. However, we also need in situ data to correct the algorithm because the $R_{\mathrm{sg}}$ increases the value of DCI.

According to the equation of BGr $\left(B G r=\frac{R_{\mathrm{rs}}(490)+R_{\mathrm{gg}}(490)}{R_{\mathrm{rs}}(560)+R_{\mathrm{gg}}(560)}\right)$, the relationship of BGr will not be affected by sun glint when $\mathrm{BGr}=1$. The Chl-a retrieval results using the value of $\mathrm{BGr}=1$ against the measured Chl-a data may help to verify whether the retrieval result is affected by sun glint.

\subsection{Bottom Effect}

To study the effect of the bottom on Chl-a concentration retrieval, we subtracted the results retrived by $r_{\text {rs }}$ (i.e., the remote sensing reflectance after removing the effect of bottom) from those by $R_{\text {rs }}$ (i.e., the remote sensing reflectance affected by the bottom). Figure 16 shows that the error caused by the effect of bottom is approximately $0-0.3 \mathrm{ug} / \mathrm{L}$. The bottom in shallow waters causes larger Chl-a concentratio retrieval results because the water-leaving reflectance contributed by a sandy bottom in the green band is larger than that of the blue band. The error spatial distritbution shows that error in the waters with $\mathrm{H}<2 \mathrm{~m}$ is low, which may be beacause the effect of the bottom not only changes with water different depths, but also in terms of turbidity. The waters near the coast contain a high concentration of NAP picked up by the sea waves. To analyze the relationship between errors caused by bottom reflectance and $\mathrm{H}$, we select three hatch lines (blue lines in Figure 16). Figure 17 shows that 
error between $\mathrm{H}=0$ and $3.8 \mathrm{~m}$ is exponential rise and that $\mathrm{H}>3.8 \mathrm{~m}$ is exponential decline, and the error maximum occurs at $\mathrm{H}=3.8 \mathrm{~m}$.

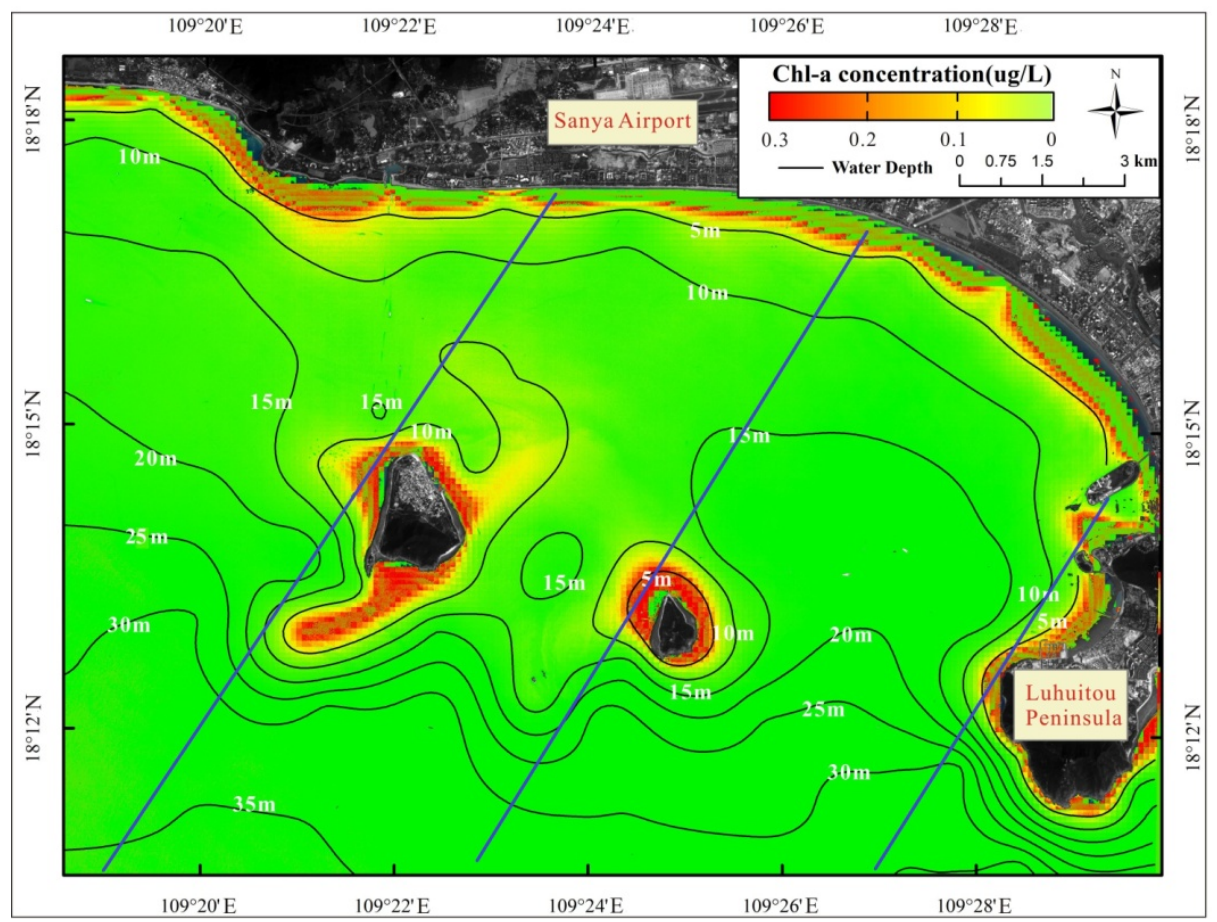

Figure 16. The difference between the results retrieved by $R_{\mathrm{rs}}$ and those by $r_{\mathrm{rs}}$.

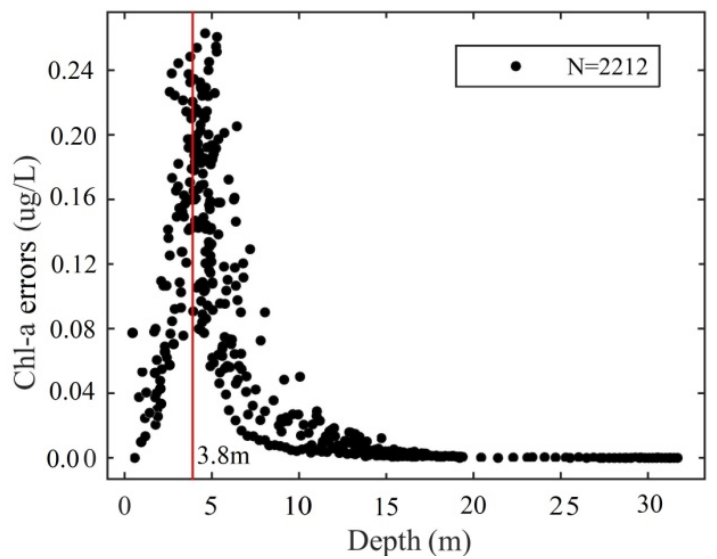

Figure 17. The errors caused by bottom reflectance against water depth $(H)$.

According to the RTM, the remote sensing reflectance contributed by $R_{\mathrm{bw}}$ depends on the bottom albedo, the water constituent, and the wavelength. A bottom of sandy coastline is mainly fine-grained sand (Figure 18a), while that of the rocky coastline is mainly coarse quartz arkose (Figure 18b), and the bottom of corals include health corals and bleaching corals donated by Chen's research [69] (Figure 18c,d). We collected the spectra of different types of bottoms to analyze the contribution of $R_{\mathrm{bw}}$ to $R_{\mathrm{rs}}$. 

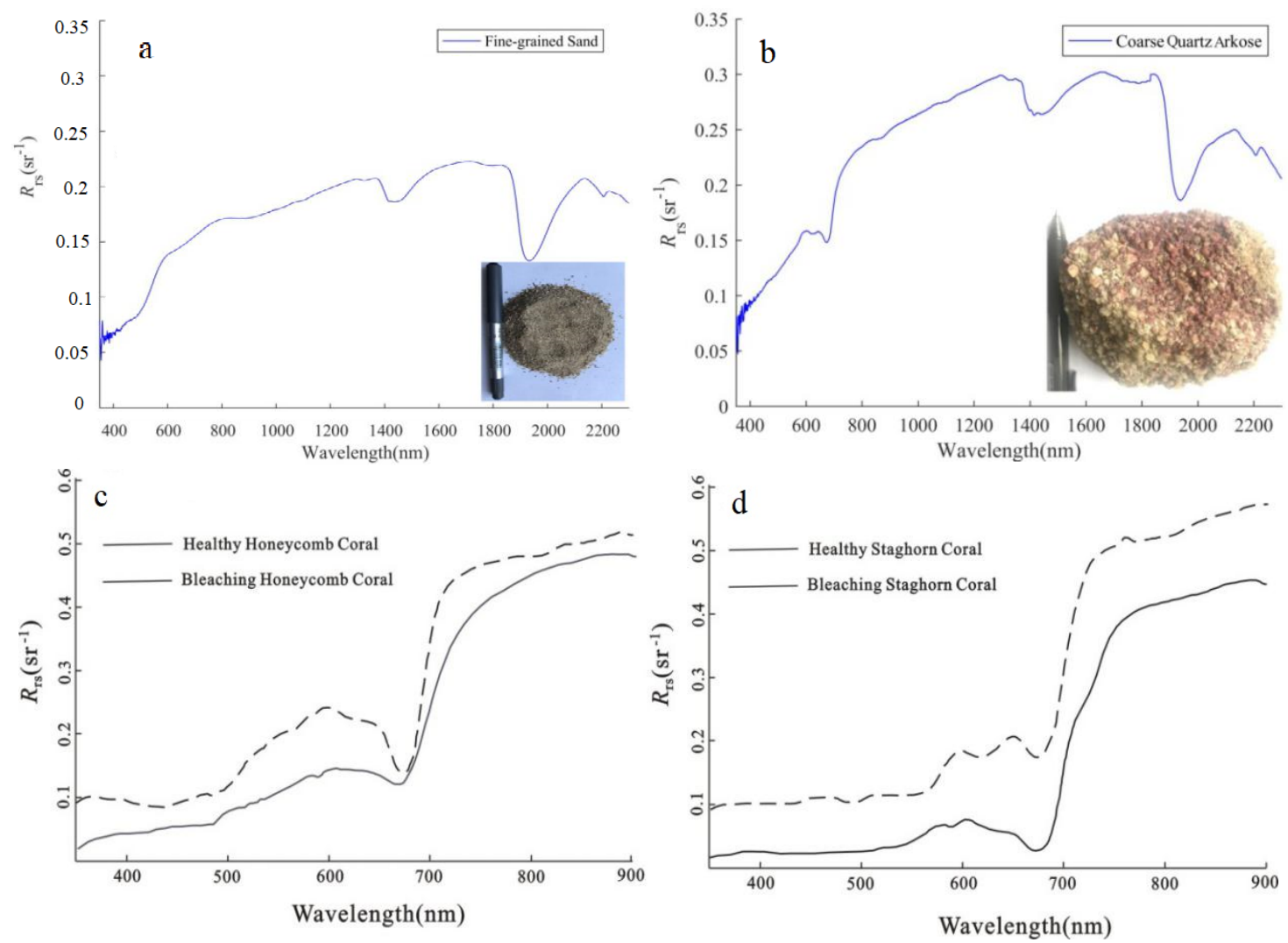

Figure 18. The spectra of different types of bottoms: (a) the fine-grained sand sample collected from a sandy coastline and its spectrum, where the sample point is at $109^{\circ} 22^{\prime} 10.36^{\prime \prime}$ and $18^{\circ} 17^{\prime} 21.40^{\prime \prime}$; (b) the coarse quartz arkose sample collected from a rocky coastline and its spectrum, where the sample point is at $109^{\circ} 22^{\prime} 10.36^{\prime \prime}$ and $18^{\circ} 17^{\prime} 21.40^{\prime \prime}$; (c) the spectra of healthy and bleaching honeycomb corals; (d) the spectra of healthy and bleaching staghorn corals.

The spectra of fine-grained sand and coarse quartz arkose are similar, and the spectra of stones are slightly higher (Figure 18a,b). Compared with sand and coarse quartz arkose, the coral spectrum has a strong absorption at $675 \mathrm{~nm}$, and the coral reflectance is relatively flat until $675 \mathrm{~nm}$ and then rises sharply after $675 \mathrm{~nm}$ (Figure 18c,d). The bottom reflectance generally increases as the wavelength increases in the visible and near-infrared bands, and we analyzed $R_{\mathrm{bw}}$ in different types of bottoms and at different water depths and wavelengths. The input parameters included the attenuation coefficient, $\mathrm{H}, \lambda$, and SGR. The IOP data were averaged from the in situ samples, and the VZA, SZA, and view azimuth angle (VAA) were obtained by SPOT6 data. The effect of the bottom on the remote sensing reflectance is shown in Figure 19.

Although the blue light has the best penetration ability, the maximum of $R_{\mathrm{bw}}$ occurs in the red band. The $R_{\mathrm{bw}}$ in the NIR band is the lowest, the water depths that affect the remote sensing reflectance are less than $2 \mathrm{~m}$, and the near-infrared band has the potential to retrieve the parameters of the water column in optically shallow waters. The green lines show the water depths when the ratio of $R_{\mathrm{bw}}$ to remote sensing reflectance is equal to $5 \%$, and the variations of the water depths on the green lines are independent of bottom types. In coastal waters, the $R_{\mathrm{bw}}$ depends on the bottom albedo when the water depth is less than $2 \mathrm{~m}$. In fact, the error caused by bottom reflectance with $H<2 \mathrm{~m}$ is low owing to the high concentration of NAP. Therefore, the $R_{\mathrm{bw}}$ mainly depends on the attenuation of the water column, and we chose four types of waters to analyze the effect of $R_{\mathrm{bw}}$ on $2 \mathrm{Br}$. In coastal waters with a low degree of pollution, the water constituent is mainly affected by terrigenous matter, and we classified coastal waters into four types based on the following [23,70,71]: (1) ultraoligotrophic waters with Chl- $a<0.3 \mathrm{ug} / \mathrm{L}$ and $N A P<3 \mathrm{mg} / \mathrm{L} ;$ (2) oligotrophic waters with $C h l-a=0.3-1 \mathrm{ug} / \mathrm{L}$ and 
$N A P=3-5 \mathrm{mg} / \mathrm{L} ;$ (3) mesotrophic waters with $C h l-a=1-5 \mathrm{ug} / \mathrm{L}$ and $N A P=5-10 \mathrm{mg} / \mathrm{L}$; and (4) eutrophic waters with Chl- $a=5-10 \mathrm{ug} / \mathrm{L}$ and NAP $=10-20 \mathrm{mg} / \mathrm{L}$. We simulated the two-band reflectance ratio and difference by water depths and water constituents to analyze the sensitivity of the parameters (Figure 20).
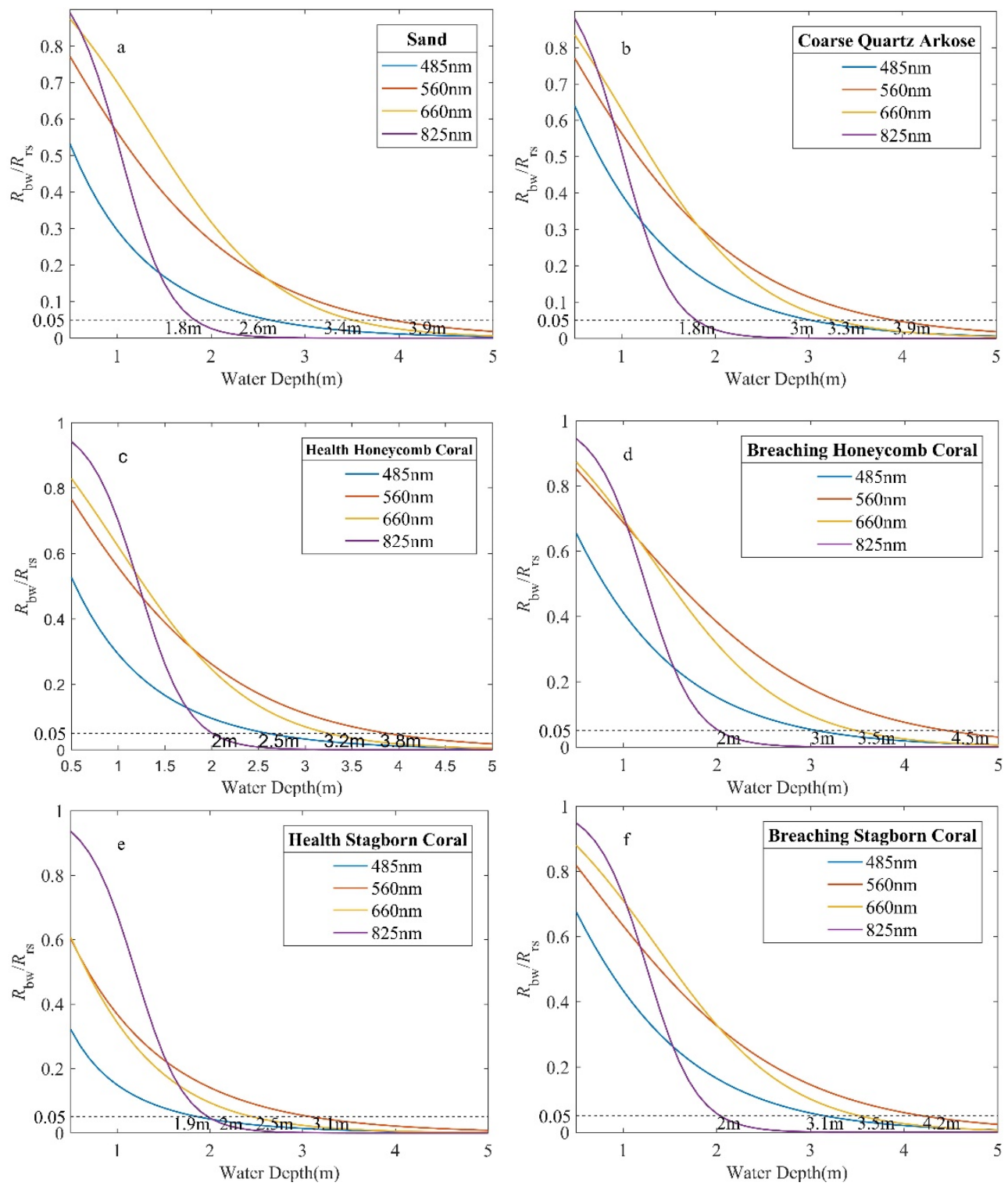

Figure 19. The effects of bottom reflectance (Rbw) on the Rrs (i.e., Rbw/R) of (a) sand, (b) coarse quartz arkose, (c) healthy honeycomb coral, (d) breaching honeycomb coral, (e) health stagborn coral, and (f) breaching stagborn coral. The black lines represent the ratio of Rbw/Rrs being equal to 0.05 . The blue, orange, yellow, and purple lines represent SPOT6 band 1, band 2, band 3, and band 4 . 

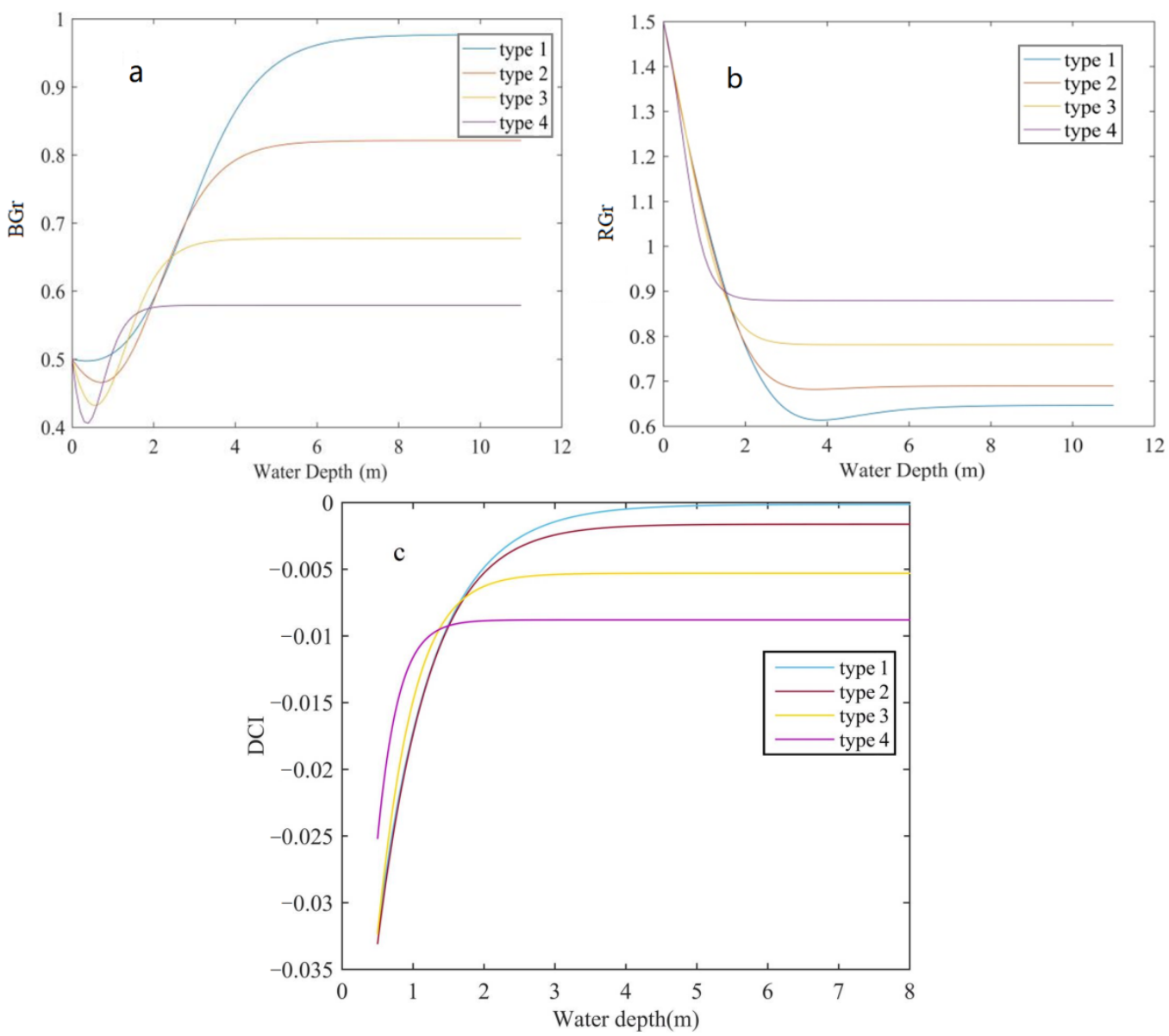

Figure 20. Plots of the (a) BGr, (b) RGr, and (c) DCI simulated by different types of waters versus water depths. Type 1, type 2, and type 3 represent ultraoligotrophic waters, oligotrophic waters, mesotrophic waters, and eutrophic waters, respectively.

The $R_{\mathrm{bw}}$ varies with the water column attenuation coefficient and bottom albedo, and it is difficult to retrieve the Chl-a concentration without information of the $R_{\mathrm{bw}}$. Figure 20 shows that the DCI is less affected by the bottom than BGr and RGr, and the optical depth for DCI is less than $2 \mathrm{~m}$ in clear waters (type 1 waters) and $1 \mathrm{~m}$ in turbid waters (type 4 waters). According to the empirical algorithms, the $R_{\mathrm{bw}}$ increases the Chl-a concentration by approximately $0-4.2 \mathrm{ug} / \mathrm{L}$ and $0-1.2 \mathrm{ug} / \mathrm{L}$ using $\mathrm{BGr}$ and DCI, respectively.

\subsection{The Effect of NAP on Spatial Distribution}

To study the effect of NAP on the distribution of the Chl-a concentration, we separated the results between those retrieved by the $r_{\text {rs }}$ and those by $a_{\text {phy }}(490)$ calculated using the semi-empirical algorithm (as shown in Figure 21). Similar to the effect of the bottom, NAP also causes larger retrieval results because the absorption coefficient of NAP in the blue band is larger than that in the green band. Figure 21 shows that the errors caused by NAP range from approximately 0.05 to $0.45 \mathrm{ug} / \mathrm{L}$. To analyze the effect of NAP on the Chl-a retrieval result, we calculated the concentration of NAP by the empirical algorithm using NIR band (as show in Appendix A.3). Figure 22 shows the distribution of NAP concentration in SYB, and the range is approximately $2.2-30.1 \mathrm{mg} / \mathrm{L}$. Shallow waters contain more $\mathrm{NAP}$, and the waters with $\mathrm{H}<5 \mathrm{~m}$ are most turbid (NAP $>25 \mathrm{mg} / \mathrm{L}$ ). Open waters contain low NAP, and the waters with $\mathrm{H}>35 \mathrm{~m}$ are clear (NAP $<5 \mathrm{mg} / \mathrm{L}$ ). We also selected the results from three hatch lines in Figure 19 to analyze the relationship between the error caused by NAP and the concentration of NAP. Figure 23 shows that the effect of NAP is positively correlated with the concentration of NAP. 


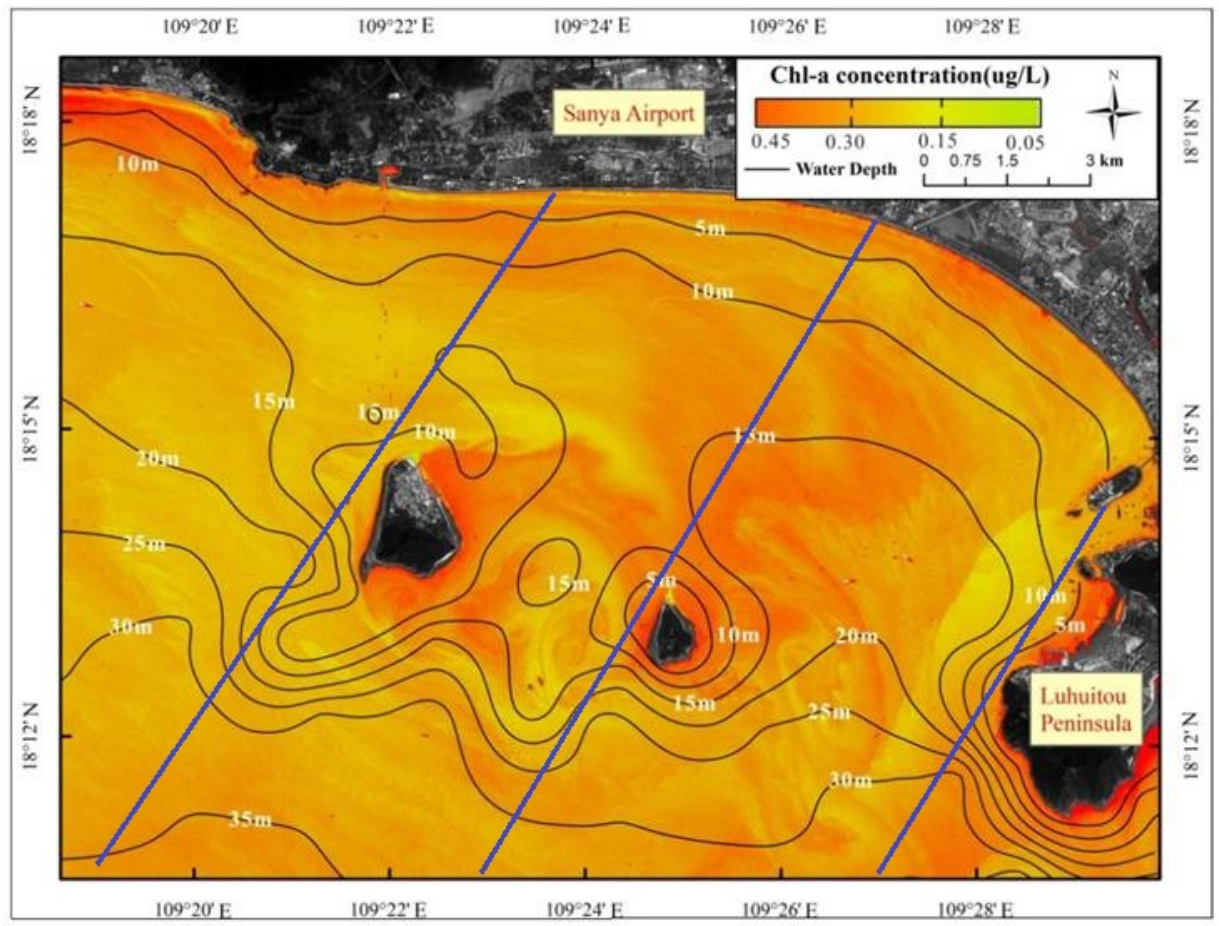

Figure 21. The difference between the concentration of Chl-a results retrived by $r_{\mathrm{rs}}$ and by $a_{\mathrm{phy}}(490)$.

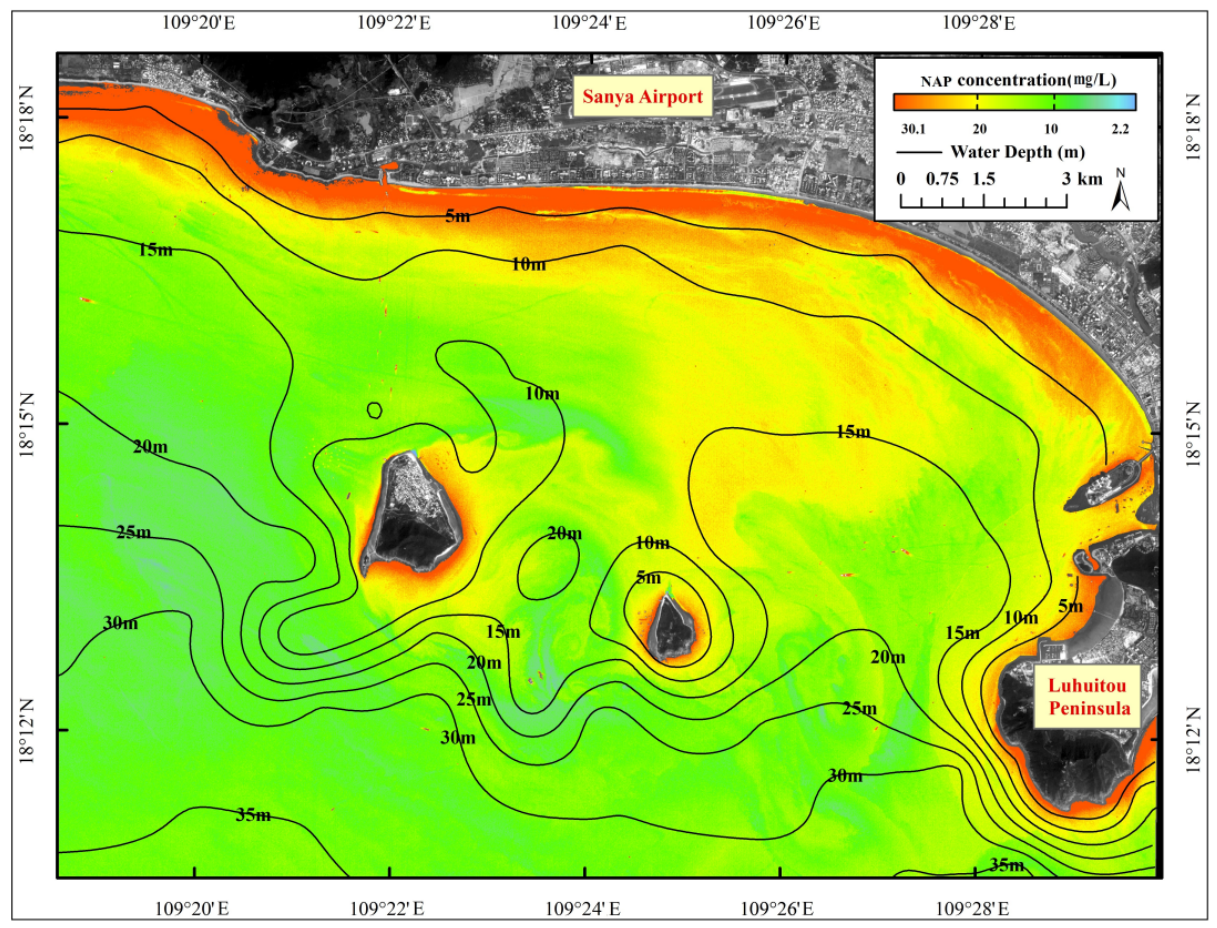

Figure 22. The concentration of NAP retrieved by the near-infrared (NIR) band of SPOT6. 


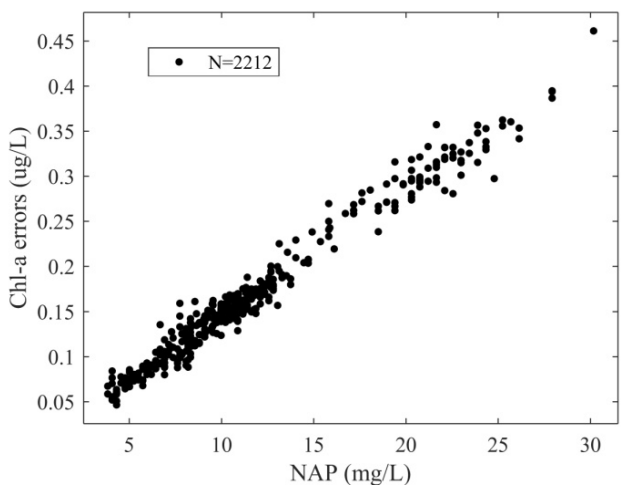

Figure 23. The concentration of NAP against the concentration of Chl-a retrieval error caused by NAP.

The two-band algorithm based on the visible bands is widely used in Chl-a concentration retrieval, but it is largely affected by NAP. Figure 24 shows the effect of NAP on the recognition ability of two-band algorithms of Chl-a. Figure 21a shows that the BGr algorithms have a stronger anti-interference ability for NAP than that of DCI and RGr in waters with NAP $<5 \mathrm{mg} / \mathrm{L}$, and the recognition ability of these three algorithms of Chl-a is not good in waters with NAP $>5 \mathrm{mg} / \mathrm{L}$. RGr and DCI lose their recognition ability of Chl-a when the concentration of NAP is larger than $9.7 \mathrm{mg} / \mathrm{L}$ and $12 \mathrm{mg} / \mathrm{L}$, respectively. Thus, we used the semi-empirical algorithm in this paper to reduce the effect of NAP.
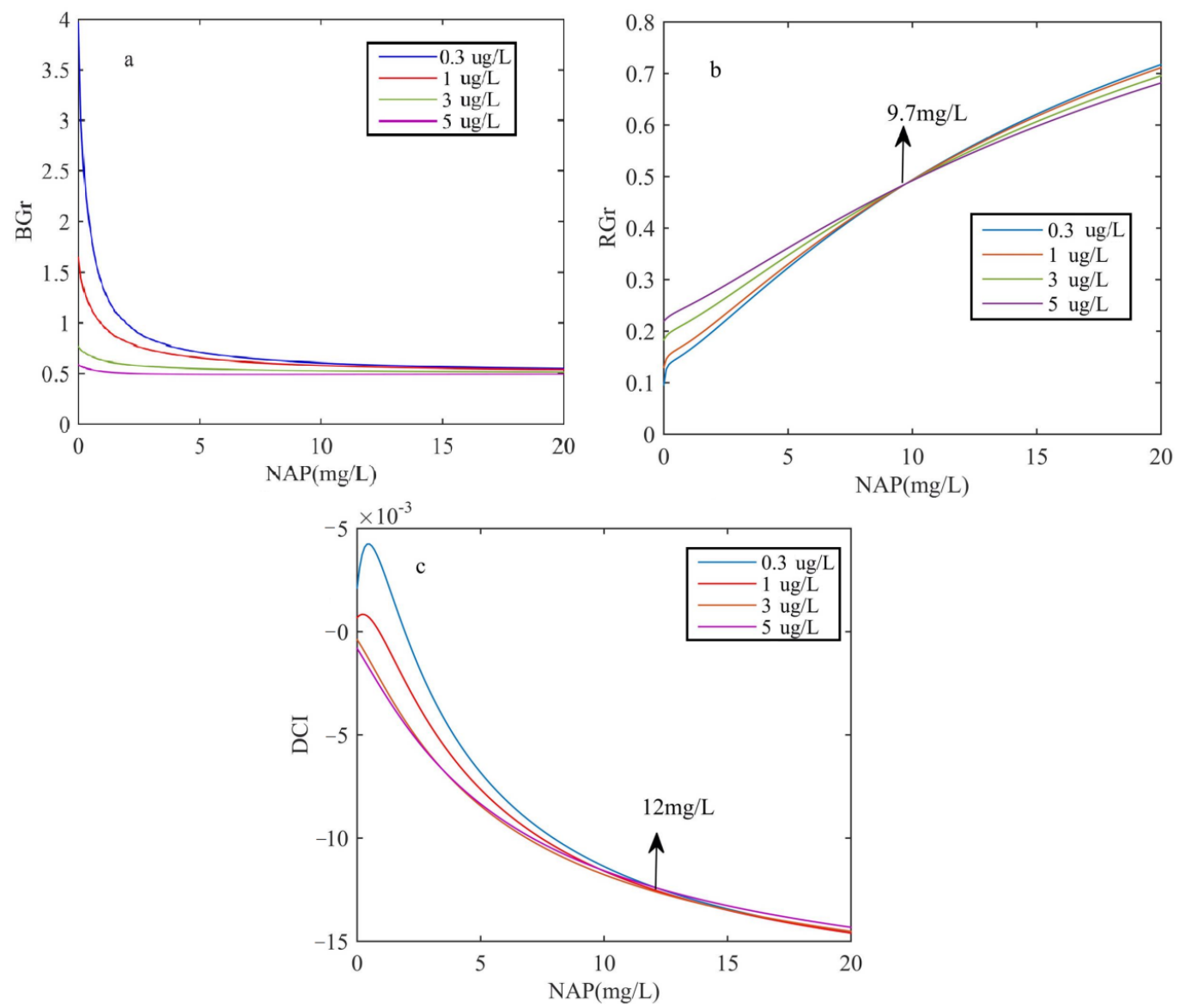

Figure 24. Plots of the two-band reflectance ratio or the difference at different concentrations of Chl-a versus the concentration of NAP. (a) BGr versus the concentrations of NAP; (b) RGr versus the concentrations of NAP; (c) DCI versus the concentrations of NAP. 


\subsection{Chl-a Retrieval of $S Y B$}

The Chl-a concentration of SYB was calculated using $a_{\text {phy }}$ (490) with the semi-empirical algorithm (Figure 25). A high concentration of Chl-a $(>1.7 \mathrm{ug} / \mathrm{L})$ is located in the areas of water depth $(H)<5 \mathrm{~m}$, and a medium concentration $(0.8-1.7 \mathrm{ug} / \mathrm{L})$ distributes in the areas of $5 \mathrm{~m}<H<10 \mathrm{~m}$, while the concentration is low $(<0.8 \mathrm{ug} / \mathrm{L})$ in the areas of $H>15 \mathrm{~m}$. In the southwest of SYB, the Chl-a concentration is lower than $0.5 \mathrm{ug} / \mathrm{L}$ in the areas of $H>20 \mathrm{~m}$, and the water type is similar to oceanic water. The concentration of Chl-a is concentrated between 0.5 and $1.1 \mathrm{ug} / \mathrm{L}$ (as shown in Figure 26), and the areas with the highest concentration of Chl-a ( $>2.5 \mathrm{ug} / \mathrm{L})$ are concentrated in harbor fishing ports, docks, and shores, while the Chl-a concentration is lowest at water depths deeper than $30 \mathrm{~m}$. The highest concentration of Chl-a occurs in the east of the Luhuitou Peninsula owing to the winter current flows from the northwest to the southeast and the barrier of the peninsula. The Chl-a concentration in the east of the study area is larger than that in the west, which is caused by the terrain and the current. The West Island and the Luhuitou Peninsula block the impact of the current and protect the coral area in the west of the island and peninsula. On the whole, the water in SYB is clear, and tourism activities such as diving are more suitable for economic activities in SYB than aquaculture in winter.

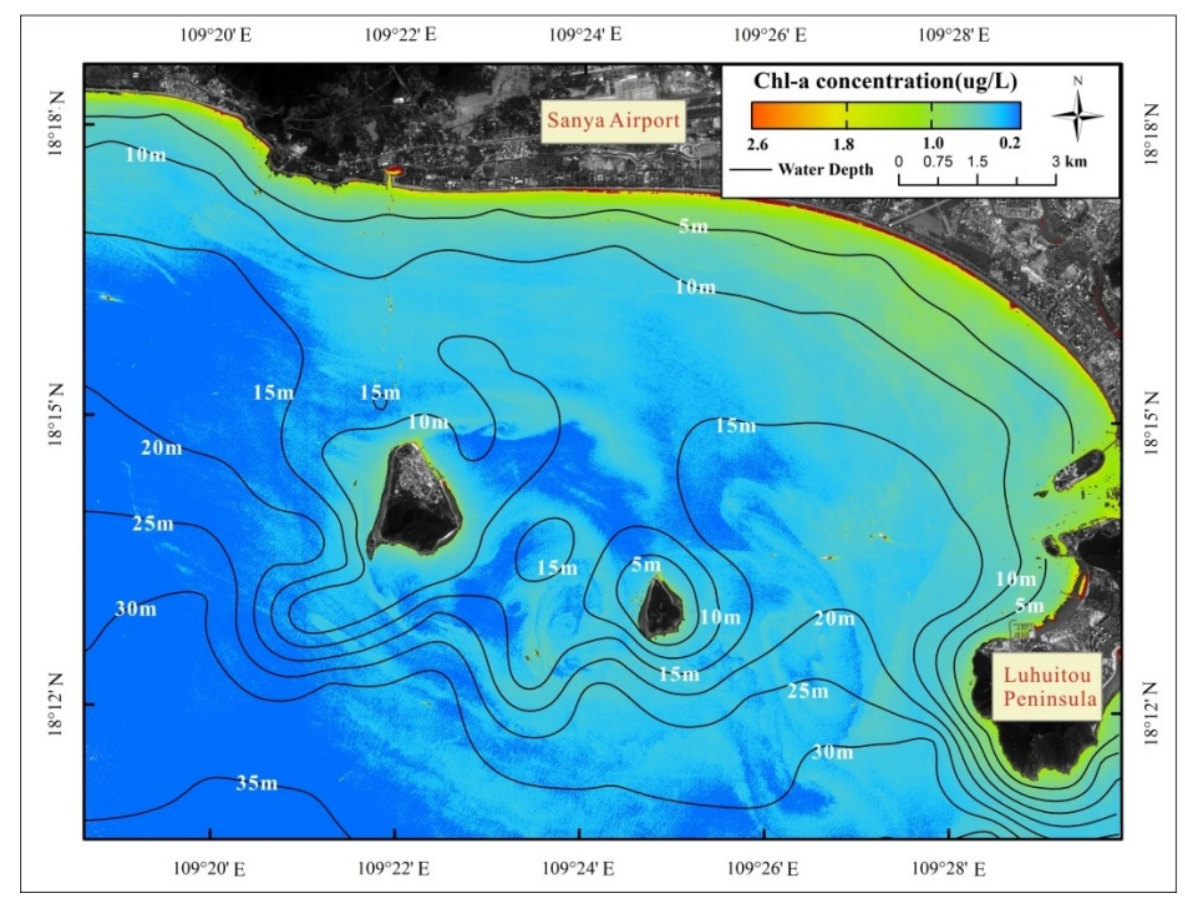

Figure 25. Chl-a concentration retrieval using $a_{\text {phy }}(490)$ in SYB. 


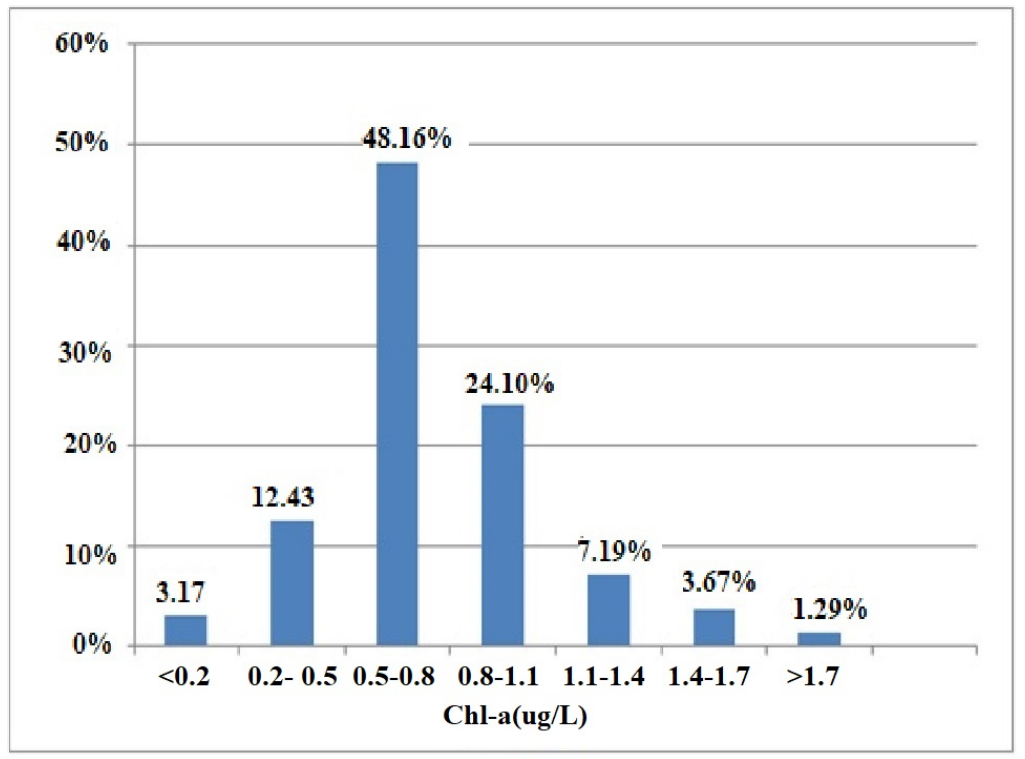

Figure 26. Chl-a concentration proportion distribution in SYB.

\section{Discussion}

We compared the results using the algorithm in this paper with the MODIS Ocean Color3 (OC3M) algorithm, which has been widely used for oceanic and coastal waters [72]. Figure 27 shows that the algorithm used in this paper is better than that of OC3M, and the RE in oligotrophic waters $(\mathrm{Chl}-\mathrm{a}<1 \mathrm{ug} / \mathrm{L})$ is greater than that in mesotrophic waters. Therefore, we needed to analyze the effect of interference factors (i.e., sun glint, bottom, and NAP) on the Chl-a retrieval algorithm. According to the water samples collected in the study area, the water types are oligotrophic and mesotrophic. Hence, we compared four common empirical algorithms to choose the best algorithm as the start of the algorithm in this paper.

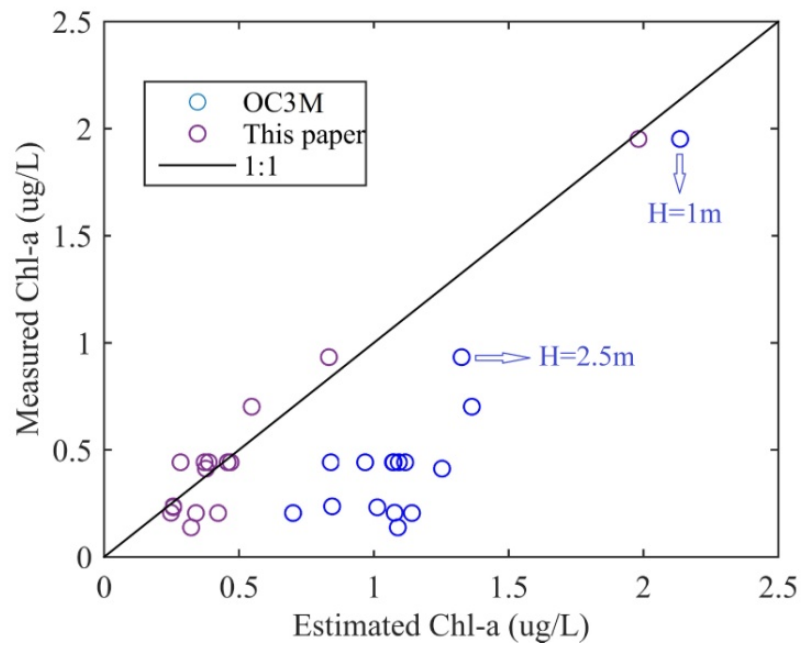

Figure 27. Comparison of the Chl-a retrieval results from the OC3M with the semi-empirical algorithm in this paper.

Figure 7 shows that the effect of $R_{\mathrm{sg}}$ on $u(\lambda)$ is larger than that of bottom reflectance, and thus it is necessary to restrain the sun glint. We used the Cox-Munk model to calculate the $R_{\mathrm{sg}}$ and Figure 13 shows that the angle of the satellite observation may be affected by sun glint when the wind is strong enough. Figure 14 also shows that the $R_{\text {rs }}$ of clear water in the NIR bands can replace the $R_{\text {sg }}$ calculated by the Cox-Munk model, and Figure 8 shows that DCI has the ability to restrain the sun glint effect. 
Figure 9 shows that, after removing the effect of $R_{\mathrm{sg}}$, both DCI and BGr have a relatively good coefficient with the Chl-a concentration.

For optically shallow waters, $R_{\mathrm{bw}}$ is non-negligible. We collected six types of bottoms and analyzed the effect of $R_{\mathrm{bw}}$ on $R_{\mathrm{rs}}$. Figure 16 shows that $R_{\mathrm{bw}}$ in the red band is higher than that in the blue band, and so $R_{\mathrm{bw}}$ causes the abnormal rise in Chl-a concentration using BGr or DCI. Figure 9 also shows that DCI is better than BGr when $R_{\mathrm{rs}}$ is affected by the bottom. $R_{\mathrm{bw}}$ decreases as $H$ gets deeper, and is lower than $5 \%$ of $R_{\mathrm{rs}}$ when $\mathrm{H}>4.5 \mathrm{~m}$. In fact, the maximum $R_{\mathrm{bw}}$ does not occur where the water depth is the lowest. Large amounts of re-suspended sediment near the coastline increase the turbidity. Figures 16 and 17 show that retrieval is most affected by bottoms at $\mathrm{H}=3.8 \mathrm{~m}$ and the biggest error is approximate $0.3 \mathrm{ug} / \mathrm{L}$.

There are more data sources from satellites for land observation than there are for coastal zone observation, and land observation satellites have the potential to be applied in coastal zones. For Chl-a retrieval in oligotrophic or mesotrophic waters, algorithms based on the blue-green band may be more suitable than algorithms based on the NIR bands [14]. Therefore, multi-spectral land observation satellites with the blue-green band can also be used for Chl-a concentration retrieval. NAP is a big barrier for Chl-a concentration retrieval using observation satellites. Thus, we used a semi-empirical algorithm to reduce the effect of NAP and to calculate $a_{\text {phy }}$ to retrieve the concentration of Chl-a. Figures 11 and 12 show that the Chl-a concentration retrieval results calculated by the semi-empirical algorithm are better than those calculated by the empirical algorithms. Figure 21 also shows that the errors caused by NAP range from 0.05 to $0.45 \mathrm{ug} / \mathrm{L}$ and Figure 23 shows that the errors caused by NAP have a good correlation with the concentration of NAP.

In order to study which parameter has a greater influence on Chl-a inversion, we simulated the errors caused by sun glint, bottom reflectance, and NAP. We set the sand spectrum, Chl-a $=1 \mathrm{ug} / \mathrm{L}$, $\mathrm{H}=3-7 \mathrm{~m}$, and $R_{\mathrm{sg}}=0.01 \mathrm{sr}^{-1}$ as the input parameters. Figure 28 shows that the error caused by bottom reflectance is lower than $0.1 \mathrm{ug} / \mathrm{L}$ when $\mathrm{H}>5 \mathrm{~m}$, and the error caused by sun glint in our study is approximately $0.11 \mathrm{ug} / \mathrm{L}$. NAP is the biggest interference factor when the concentration of $\mathrm{NAP}>9.5 \mathrm{mg} / \mathrm{L}$. Figure 25 also shows that the concentration of NAP in the bay mouth is higher than $15 \mathrm{mg} / \mathrm{L}$, and is lower than $5 \mathrm{mg} / \mathrm{L}$ in $\mathrm{H}>30$. Hence, the $R_{\mathrm{bw}}$ of $\mathrm{H}<5 \mathrm{~m}$ should be considered and the $\mathrm{NAP}$ is the biggest interference factor in the semi-enclosed bay.

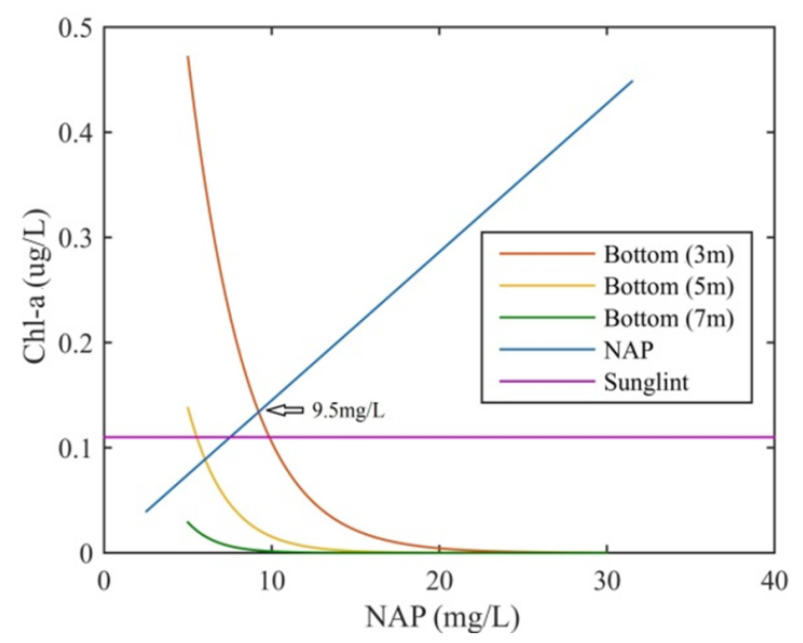

Figure 28. Errors caused by sun glint, bottom reflectance, and NAP versus the concentration of the NAP. The NAP is the primary source of error when NAP $>9.5 \mathrm{mg} / \mathrm{L}$.

In winter, the Luhuitou Peninsula on the east side of SYB blocks out suspended matter brought by the southeast current, and the semi-enclosed terrain keeps in more suspended matter and provides more nutrients for phytoplankton near the shore. However, the water of SYB is not highly nutritive in winter (Figure 25). According to the Chl-a retrieval algorithm (i.e., $\mathrm{Chl}-\mathrm{a}=\mathrm{A} \cdot a_{\mathrm{phy}}{ }^{\mathrm{B}}$ ), the empirical 
coefficients of A and B change with the $a_{\text {phy' }}^{*}$ which changes with the types of phytoplankton. The Lee's dataset taken over the shallow waters along the west Florida shelf, Key West, Fla., and the Bahamas showed that $a_{\text {phy }}^{*}(490)$ ranged from 0.03 to $0.17 \mathrm{~m}^{2} \mathrm{mg}^{-1}$ [32], and the Neil's dataset measured from Irish Sea and the Bristol Channel shows that $a_{\text {phy }}^{*}(490)$ ranges from 0.02 to $0.22 \mathrm{~m}^{2} \mathrm{mg}^{-1}$ [46]. Therefore, the change in the types of phytoplankton may be another source of error in this algorithm.

\section{Conclusions}

We proposed a semi-empirical Chl-a retrieval algorithm for SPOT6 data as a demonstration for multi-spectral data, and we applied it to the waters in SYB. A comparison of the performance of this semi-empirical algorithm with that of the OC3M algorithm, and a concurrent measurement of the concentration of Chl-a from 16 surface water points in SYB, demonstrated the appropriateness of the semi-empirical algorithm to estimate the Chl-a concentration in coastal waters using SPOT6 data $\left(\mathrm{R}^{2}=0.93\right.$ with an RMSE $=0.11 \mathrm{ug} / \mathrm{L}$ and $\left.\mathrm{MAPE}=21 \%\right)$.

Through a comparison of the Chl-a concentration retrieval results using different algorithms and the sensitivity of $R_{\mathrm{sg}}, R_{\mathrm{bw}}$, and NAP to two-band algorithms (e.g., $\mathrm{BGr}, \mathrm{RGr}, \mathrm{CI}$, and DCI), algorithms that use the blue-green band are available for oligotrophic and mesotrophic coastal waters. DCI is a better empirical algorithm than BGr because it has a stronger anti-interference ability in terms of sun glint and bottom reflectance. To improve the accuracy of the empirical algorithm, we calculated the total absorption coefficient and the absorption coefficient of each component by empirical algorithms, and then created the Chl-a concentration retrieval semi-empirical algorithm in the form of Chl-a $=\mathrm{A}\left[a_{\mathrm{phy}}(490)\right]^{\mathrm{B}}$, where $\mathrm{A}=43.3$ and $\mathrm{B}=1.454$. The empirical coefficients of $\mathrm{A}$ and $\mathrm{B}$ can be calculated by the in situ data of the Chl-a concentration or $a_{\text {phy }}^{*}(490)$, which changes with the types of phytoplankton.

In the case of ignoring $R_{\mathrm{sg}}$ unrelated to IOPs, NAP is the biggest interference factor when the concentration of NAP $>9.5 \mathrm{mg} / \mathrm{L}$ and the effect of bottom reflectance should be considered when $\mathrm{H}<5 \mathrm{~m}$ in SYB. The errors caused by NAP and the concentration of NAP are positively and linearly correlated, and the biggest error caused by the bottom occurs at $\mathrm{H}=2.5 \mathrm{~m}$.

In SYB, the Chl-a concentration retrieved by SPOT6 data ranges from 0.2 to $2.6 \mathrm{ug} / \mathrm{L}$, and the concentration of NAP ranges from 2.2 to $30.1 \mathrm{mg} / \mathrm{L}$. In general, the IOPs of coastal waters in Sanya are dominated by NAP. The distribution of the Chl-a concentration retrieval results shows that the terrain and the current affect the distribution of the Chl-a concentration. The West Island and the Luhuitou Peninsula block the impact of the southeast winter current and protect the phytoplankton in the coral areas. In general, the Chl-a concentration in shallow waters is higher than that in deep waters, and terrigenous matter may be the main source of nutrients for phytoplankton.

Compared with the remote sensing data from ocean color satellites, the data from land observation satellites have the advantage of higher spatial resolution and more data sources. Though most land observation sensors have the disadvantage of low spectral resolution and lack of NIR bands around $705 \mathrm{~nm}$, the data of land observation satellites have potential for application to oligotrophic or mesotrophic coastal waters. The semi-empirical algorithm based on SPOT6 reflectance data can be used for $\mathrm{Chl}-\mathrm{a}$ concentration retrieval in optically shallow areas of coastal waters after removing the effects of sun glint, bottom reflectance, and NAP, and it also has the potential to monitor Chl-a in optically shallow waters with a high NAP concentration using other broad-band remote sensing data without the red-edge band (e.g., Landsat8 OLI, ASTER, and GaoFen2).

Author Contributions: Data curation, Y.Y. and T.L.; Formal analysis, Y.C.; Funding acquisition, S.C.; Methodology, Y.Y. and J.L.; Visualization, Y.Y.; Writing—original draft, Y.Y.; Writing—review \& editing, S.C. and W.Q. All authors have read and agreed to the published version of the manuscript.

Funding: This research was funded by the Program for JLU Science and Technology Innovative Research Team (No. 2017TD-26) and the Plan for Changbai Mountain Scholars of Jilin Province, China. 
Acknowledgments: The authors would like to thank to Kaishan Song scientific research team of the Northeast Institute of Geography and Agroecology for the measurement data of IOPs and water constituents, and Guangzhou Marine Geological Survey of China for the data of water depth.

Conflicts of Interest: The authors declare no conflict of interest.

\section{Appendix A.}

\section{Appendix A.1. The Relative Spectral Response Function (RSRF) of SPOT6 Data}

The SPOT6 data have four visible bands (blue band: 450-520 nm; green band: 530-590 nm; red band: $625-695 \mathrm{~nm}$ ) and one near-infrared (NIR) band $(760-890 \mathrm{~nm})$, and the spatial resolution is $6 \mathrm{~m}$. In the application of ocean color remote sensing, the visible bands and the NIR band are used for monitoring phytoplankton and NAP, respectively. The Chl-a absorption peaks are located in the blue and red bands (Figure A1).

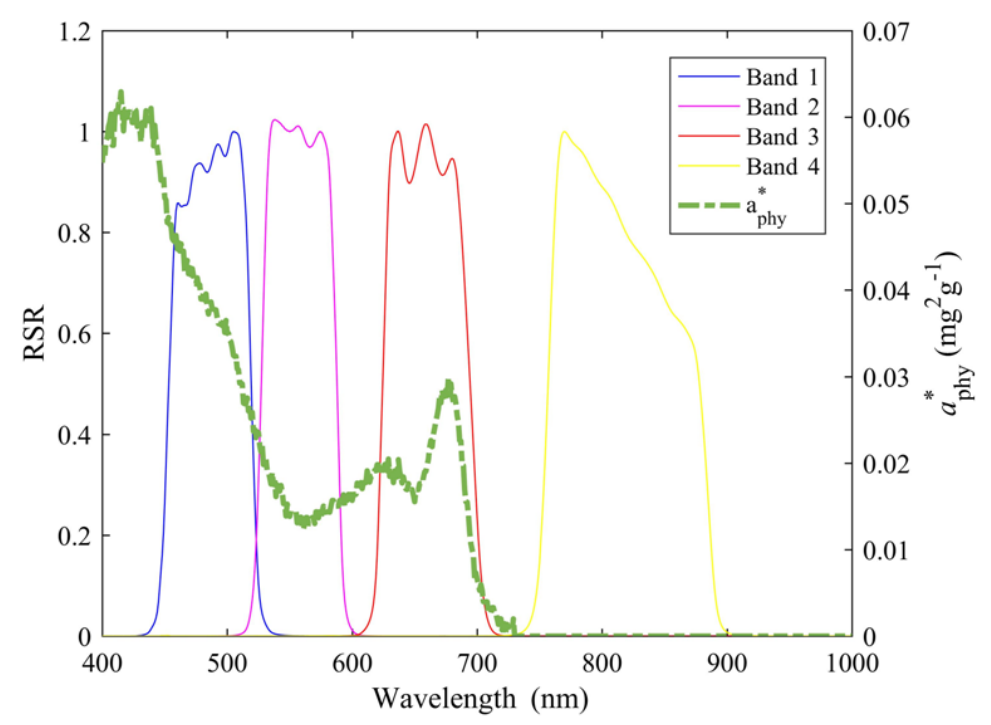

Figure A1. The relative spectral response function (RSRF) of the SPOT6 and spectral absorption coefficient of chlorophyll-a $\left(a_{\text {phy }}{ }^{*}\right)$ measured by in situ samples.

Appendix A.2. Diffuse Attenuation Coefficient

Upwelling and downwelling diffuse attenuation coefficients $\left(k_{\mathrm{u}}\right.$ and $\left.k_{\mathrm{d}}\right)$ are the function of the sun-satellite polar direction and inherent optical properties (IOPs) [32]:

$$
\begin{gathered}
k_{\mathrm{d}}=1.0546 \cdot\left(a+b_{\mathrm{b}}\right) / \cos \theta_{0}^{\prime} \cdot k_{\mathrm{d}} \\
k_{\mathrm{d}}=1.03\left(1+\frac{b_{\mathrm{b}}}{a+b_{\mathrm{b}}}\right)^{2.2658} \cdot\left(1+\frac{0.0577}{\cos \theta_{0}}\right) \cdot \frac{a+b_{\mathrm{b}}}{\cos \theta^{\prime}}
\end{gathered}
$$

where $k, \theta_{0}{ }^{\prime}$, and $\theta^{\prime}$ are the vertical attenuation coefficient, the incident angle underwater surface, and the outside angle underwater surface, respectively. The total absorption coefficient $(a)$ and the total backscattering coefficient $\left(b_{\mathrm{b}}\right)$ can be calculated by Equation (18), and the incident $\left(\theta_{0}{ }^{\prime}\right)$ and outside $\left(\theta^{\prime}\right)$ angles under the water surface are derived as follows:

$$
\begin{aligned}
& \theta^{\prime}=\sin ^{-1}\left[\frac{1}{n} \sin \left(\theta+\theta_{\mathrm{n}}\right)\right]-\theta_{\mathrm{n}} \\
& \theta_{0}^{\prime}=\sin ^{-1}\left[\frac{1}{n} \sin \left(\theta_{0}+\theta_{\mathrm{n}}\right)\right]-\theta_{\mathrm{n}}
\end{aligned}
$$




\section{Appendix A.3. Estimating the NAP Concentration}

In coastal waters, NAP affects the absorption and scattering coefficients and is used to estimate the water column attenuation coefficient $\left(k_{\mathrm{u}}\right.$ and $\left.k_{\mathrm{d}}\right)$. An iterative fitting NAP retrieval model was proposed by Tassan [73]:

$$
N A P=10^{\left\{0.649+25.623\left[R_{\mathrm{rs}}(555)+R_{\mathrm{rs}}(670)\right]-0.646\left(\frac{R_{\mathrm{rs}}(490)}{R_{\mathrm{rs}}(555)}\right)\right\}}
$$

The Tassan model was originally designed for SeaWIFS, and we replaced the SeaWIFS bands (i.e., $R_{\mathrm{rs}}(490), R_{\mathrm{rs}}(555)$, and $R_{\mathrm{rs}}(670)$ ) with SPOT6 bands (i.e., $R_{\mathrm{rs}}(490), R_{\mathrm{rs}}(560)$, and $R_{\mathrm{rs}}(660)$ ). However, the visible bands are obviously affected by bottom reflectance. The bottom effect in the NIR band is very little owing to the strong absorption of water, which provides the ideal conditions for NAP concentration retrieval in shallow waters. Though the NIR band of SPOT6 data is not available for Chl-a retrieval, there is a good correlation between NAP and remote sensing reflectance (Figure A2).
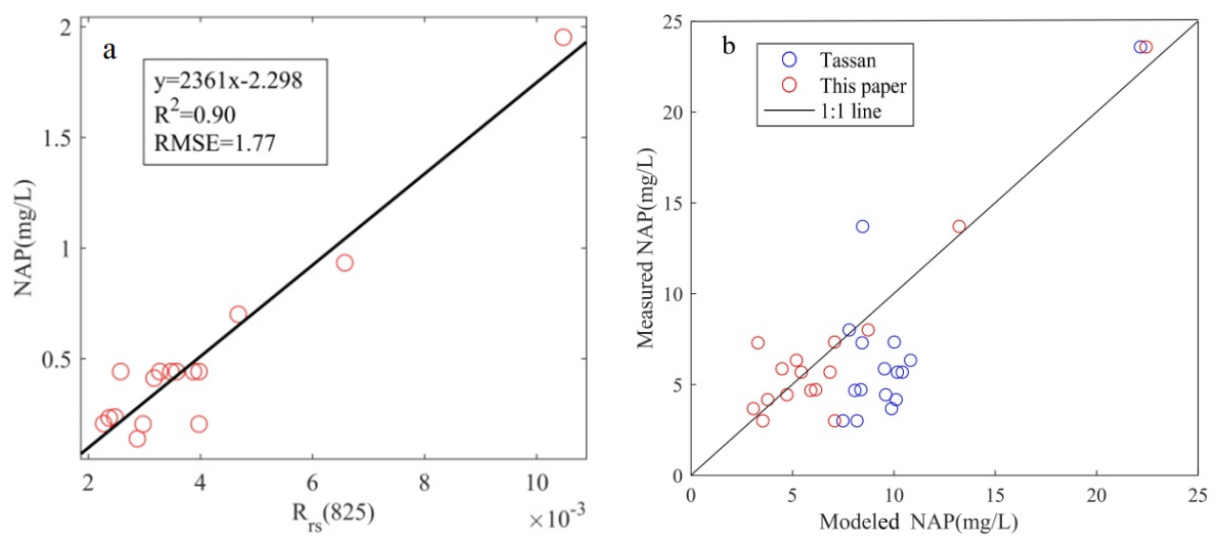

Figure A2. (a) Scatter plot of the estimated versus measured concentration of non-algal particles (NAPs) using near-infrared (NIR) remote sensing reflectance of SPOT6 (SPOT (825)). (b) Scattergram of the concentration of Chl-a between the sample value and the estimation by the Tassan model and the model in this paper.

\section{Appendix A.4. Absorption Coefficient of the Colored Dissolved Organic Matter (CDOM) Estimation}

$\mathrm{CDOM}$ can be estimated using a ratio of reflectance at wavelengths $>600 \mathrm{~nm}$ to reflectance in the $400-550 \mathrm{~nm}$ range [74-76]. The $a_{\mathrm{CDOM}}$ at $250 \mathrm{~nm}$ has a good correlation with the ratio of $r_{\mathrm{rs}}(650)$ to $r_{\mathrm{rs}}(490)$ (Figure A3).

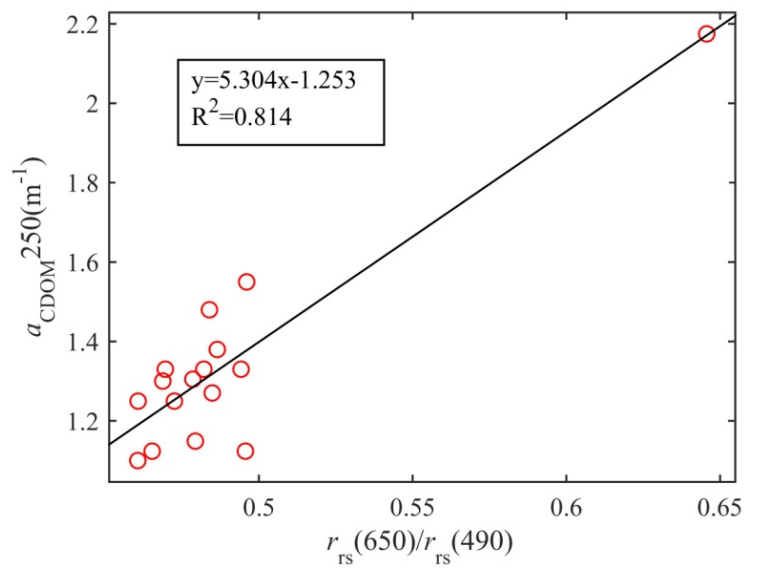

Figure A3. $a_{\mathrm{CDOM}}$ at $250 \mathrm{~nm}$ versus the ratio of $r_{\mathrm{rs}}(650)$ to $r_{\mathrm{rs}}(490)$. 
The $a_{\mathrm{CDOM}}$ at $490 \mathrm{~nm}$ and $560 \mathrm{~nm}$ can be calculated as follows [77]:

$$
a_{\mathrm{CDOM}}(\lambda)=a_{\mathrm{CDOM}}\left(\lambda_{0}\right) \exp \left[S\left(\lambda_{0}-\lambda\right)\right]
$$

where $S$ is the spectral slope of the $a_{\mathrm{CDOM}}$ and $\lambda_{0}=250 \mathrm{~nm} . S=0.0127$, derived from the in situ $a_{\mathrm{CDOM}}$ (250) and $a_{\mathrm{CDOM}}(440)$ [78].

\section{References}

1. Mcgranahan, G.; Balk, D.; Anderson, B. The Rising Tide: Assessing the Risks of Climate Change and Human Settlements in Low Elevation Coastal Zones. Environ. Urban. 2007, 19, 17-37. [CrossRef]

2. Blondeau-Patissier, D.; Gower, J.F.R.; Dekker, A.G.; Phinn, S.R.; Brando, V.E. A Review of Ocean Color Remote Sensing Methods and Statistical Techniques for the Detection, Mapping and Analysis of Phytoplankton Blooms in Coastal and Open Oceans. Prog. Oceanogr. 2014, 123, 123-144. [CrossRef]

3. Yu, Y.; Chen, S.; Lu, T.Q.; Tian, S. Coastal Disasters and Remote Sensing Monitoring Methods. In Sea Level Rise and Coastal Infrastructure, 1st ed.; Zhang, Y.Z., Hou, Y.J., Eds.; IntechOpen: London, UK, 2018; pp. 119-138. [CrossRef]

4. Gordon, H.R.; Morel, A.Y. Remote Assessment of Ocean Color for Interpretation of Satellite Visible Imagery. In A Review Lecture Notes on Coastal and Estuarine Studies; Springer: New York, NY, USA, 1983; Volume 4, p. 114.

5. Morel, A. Optical Modeling of the Upper Ocean in Relation to its Biogenous Matter Content (Case-1 Waters). J. Geophys. Res. Oceans 1988, 93, 10749-10768. [CrossRef]

6. Aiken, J.; Moore, G.F.; Trees, C.C.; Hook, S.B.; Clark, D.K. The SeaWiFS CZCS-type pigment algorithm. In SeaWiFS Technical Report Series; Goddard Space Flight Center: Greenbelt, MD, USA, 1995.

7. Carder, K.L.; Chen, F.R.; Cannizzaro, J.P.; Campbell, J.W.; Mitchell, B.G. Performance of the MODIS Semi-analytical Ocean Color Algorithm for Chlorophyll-a. Adv. Space Res. 2004, 33, 1152-1159. [CrossRef]

8. Ha, N.T.T.; Koike, K.; Nhuan, M.T. Improved Accuracy of Chlorophyll-a Concentration Estimates from MODIS Imagery Using a Two-Band Ratio Algorithm and Geostatistics: As Applied to the Monitoring of Eutrophication Processes over Tien Yen Bay (Northern Vietnam). Remote Sens. 2014, 6, 421-442. [CrossRef]

9. Gordon, H.R.; Clark, D.K.; Brown, J.W.; Brown, O.B.; Evans, R.H. Phytoplankton Pigment Concentrations in the Middle Atlantic Bight: Comparison of Ship Determinations and CZCS Estimates. Appl. Opt. 1983, 22, 20-36. [CrossRef]

10. O’Reilly, J.E.; Maritorena, S.; Mitchell, B.G.; Siegel, D.A.; Carder, K.L.; Garver, S.A.; Kahru, M.; McClain, C. Ocean Color Chlorophyll Algorithms for SeaWiFS. J. Geophys. Res. 1998, 103, 24937-24953. [CrossRef]

11. O’Reilly, J.E.; Maritorena, S.; Mitchell, B.G.; Siegel, D.A.; Carder, K.L.; Garver, S.A.; Kahru, M.; McClain, C. Ocean Color Chlorophyll a Algorithms for SeaWiFS, OC2, and OC4: Version 4. In SeaWiFS Postlaunch Calibration and Validation Analyses, Part 3, SeaWiFS Postlaunch Technical Report Series; Hooker, S.B., Firestone, E.R., Eds.; NASA Goddard Space Flight Center: Greenbelt, MD, USA, 2000; Volume 11, pp. 9-23.

12. Carder, K.L.; Chen, F.R.; Lee, Z.P.; Hawes, S.K.; Cannizzaro, J.P. MODIS Ocean Science Team Algorithm Theoretical Basis Document, ATBD 19, Case 2 Chlorophyll-a, Version 7. Available online: http://modis.gsfc. nasa.gov/data/atbd/atbd_mod19.pdf.2003 (accessed on 6 June 2014).

13. Thu, H.N.T.; Phuong, T.N.T.; Katsuaki, K.; Trong, N.M. Selecting the Best Band Ratio to Estimate Chlorophyll-a Concentration in a Tropical Freshwater Lake Using Sentinel 2a Images from a Case Study of Lake Ba Be (Northern Vietnam). ISPRS Int. J. Geo-Inf. 2017, 6, 290.

14. Liu, G.; Li, L.; Song, K.S.; Li, Y.M.; Lyu, H.; Wen, Z.; Fang, C.; Bi, S.; Sun, X.; Wang, Z.; et al. An OLCI-based Algorithm for Semi-Empirically Partitioning Absorption Coefficient and Estimating Chlorophyll a Concentration in Various Turbid Case-2 Waters. Remote Sens. Environ. 2020, 239. [CrossRef]

15. Lee, Z.P.; Carder, K.L.; Arnone, R.A. Deriving Inherent Optical Properties from Water Color: A Multiband Quasi-analytical Algorithm for Optically Deep Waters. Appl. Opt. 2002, 41, 5755-5772. [CrossRef]

16. Chen, J.; Zhang, X.; Quan, W. Retrieval Chlorophyll-a Concentration from Coastal Waters: Three-band Semi-Analytical Algorithms Comparison and Development. Opt. Express 2013, 21, 9024-9042. [CrossRef] [PubMed] 
17. Chen, J.; Quan, W.; Wen, Z.; Cui, T. An Improved Three-band Semi-analytical Algorithm for Estimating Chlorophyll-a Concentration in Highly Turbid Coastal Waters: A Case Study of the Yellow River Estuary, China. Environ. Earth Sci. 2013, 69, 2709-2719. [CrossRef]

18. Gitelson, A.A.; Dall'Olmo, G.; Moses, W.; Rundquist, D.C.; Barrow, T.; Fisher, T.R.; Gurlin, D.; Holz, J. A Simple Semi-Analytical Model for Remote Estimation of Chlorophyll-a in Turbid Waters: Validation. Remote Sens. Environ. 2008, 112, 3582-3593. [CrossRef]

19. Matthews, M.W.; Bernard, S.; Winter, K. Remote Sensing of Cyanobacteria-Dominant Algal Blooms and Water Quality Parameters in Zeekoevlei, a Small Hypertrophic Lake, Using MERIS. Remote Sens. Environ. 2010, 114, 2070-2087. [CrossRef]

20. Gilerson, A.A.; Gitelson, A.A.; Zhou, J.; Gurlin, D.; Moses, W.; Ioannou, I.; Ahmed, S.A. Algorithms for Remote Estimation of Chlorophyll-a in Coastal and Inland Waters Using Red and Near-infrared Bands. Opt. Express 2010, 18, 24109-24125. [CrossRef] [PubMed]

21. Toming, K.; Kutser, T.; Laas, A.; Sepp, M.; Paavel, B.; Nõges, T. First Experiences in Mapping Lake Water Quality Parameters with Sentinel-2 MSI Imagery. Remote Sens. 2016, 8, 640. [CrossRef]

22. Dahanayaka, D.D.G.L.; Tonooka, H.; Wijeyaratne, M.J.S.; Minato, A.; Ozawa, S. Two Decadal Trends of Surface Chlorophyll-a Concentrations in Tropical Lagoon Environments in Sri Lanka Using Satellite and In-situ data. Asian J. Geoinform. 2013, 13, 7-16.

23. Fernanda, W.; Enner, A.; Thanan, R.; Nilton, I.; Cláudio, B.; Luiz, R. Estimation of Chlorophyll-a Concentration and the Trophic State of the Barra Bonita Hydroelectric Reservoir Using OLI/Landsat-8 Images. Int. J. Environ. Res. Public Health 2015, 12, 10391-10417. [CrossRef]

24. Ha, N.T.T.; Koike, K.; Nhuan, M.T.; Canh, B.D.; Thao, N.T.P.; Parsons, M. Landsat 8/OLI Two Bands Ratio Algorithm for Chlorophyll-a Concentration Mapping in Hypertrophic Waters: An Application to West Lake in Hanoi (Vietnam). IEEE J. Sel. Top. Appl. Earth Obs. Remote Sens. 2017, 10, 4919-4929. [CrossRef]

25. Cox, C.; Munk, W. Statistics of the Sea Surface Derived from Sun Glitter. J. Mar. Res. 1954, 13, $198-227$.

26. Cox, C.; Munk, W. Slopes of the Sea Surface Deduced from Photographs of Sun Glitter. Bull Scripps Inst. Oceanogr. Univ. Calif. 1956, 6, 401-488.

27. Zhang, H.; Wang, M. Evaluation of Sun Glint Models Using MODIS Measurements. J. Quant. Spectrosc. Radiat. Transf. 2010, 111, 492-506. [CrossRef]

28. Zhang, H.; Yang, K.; Lou, X.; Li, Y.; Zheng, G.; Wang, J.; Wang, X.; Ren, L.; Li, D.; Shi, A. Observation of Sea Surface Roughness at a Pixel Scale Using Multi-angle Sun Glitter Images Acquired by the ASTER Sensor. Remote Sens. Environ. 2018, 208, 97-108. [CrossRef]

29. Hu, C. An Empirical Approach to Derive MODIS Ocean Color Patterns under Severe Sun Glint. Geophys. Res. Lett. 2011, 38. [CrossRef]

30. Harmel, T.; Chami, M.; Tormos, T.; Reynaud, N.; Danis, P.A. Sunglint Correction of the Multi-Spectral Instrument (MSI)-Sentinel-2 Imagery over inland and Sea Waters from SWIR Bands. Remote Sens. Environ. 2017, 204, 308-321. [CrossRef]

31. Hlaing, S.; Gilerson, A.; Harmel, T.; Tonizzo, A.; Weidemann, A.; Arnone, R.; Ahmed, S. Assessment of a Bidirectional Reflectance Distribution Correction of above Water and Satellite Water-Leaving Radiance in Coastal Waters. Appl. Opt. 2012, 51, 220-237. [CrossRef]

32. Lee, Z.; Carder, K.L.; Mobley, C.D.; Steward, R.G.; Patch, J.S. Hyperspectral Remote Sensing for Shallow Waters: 2. Deriving Bottom Depths and Water Properties by Optimization. Appl. Opt. 1999, 38, 3831-3843. [CrossRef]

33. Lee, Z.; Carder, K.L.; Hawes, S.K.; Steward, R.G.; Peacock, T.G.; Davis, C.O. Model for the Interpretation of Hyperspectral Remote-Sensing Reflectance. Appl. Opt. 1994, 33, 5721-5732. [CrossRef]

34. Lee, Z.; Carder, K.L.; Mobley, C.D.; Steward, R.G.; Patch, J.S. Hyperspectral Remote Sensing for Shallow Waters: 1. A Semianalytical Model. Appl. Opt. 1998, 37, 6329-6338. [CrossRef]

35. Albert, A.; Mobley, C. An Analytical Model for Subsurface Irradiance and Remote Sensing Reflectance in Deep and Shallow Case-2 Waters. Opt. Express 2003, 11, 2873-2890. [CrossRef]

36. Conrad, C.; Fritsch, S.; Zeidler, J.; Rucker, G.; Dech, S. Per-Field Irrigated Crop Classification in Arid Central Asia Using SPOT and ASTER Data. Remote Sens. 2010, 2, 1035-1056. [CrossRef]

37. Ali, H.T.O.; Niculescu, S.; Sellin, V.; Bougault, C. Contribution of the New satellites (Sentinel-1, Sentinel-2, and SPOT-6) to the Coastal Vegetation Monitoring in the Pays de Brest (France). In Remote Sensing for Agriculture, Ecosystems, and Hydrology XIX; International Society for Optics and Photonics: Bellingham, WA, USA, 2017; Volume 10421, p. 1042129. 
38. Motlagh, M.G.; Kafaky, S.B.; Mataji, A.; Akhavan, R. Estimating and Mapping Forest Biomass Using Regression Models and SPOT-6 Images (Case Study: Hyrcanian Forests of North of Iran). Environ. Monit. Assess. 2018, 190, 352. [CrossRef] [PubMed]

39. Ritchie, J.C.; Zimba, P.V.; Everitt, J.H. Remote Sensing Techniques to Assess Water Quality. Photogramm. Eng. Remote Sens. 2003, 69, 695-704. [CrossRef]

40. Dekker, A.G.; Peters, S.W.M. The use of the Thematic Mapper for the Analysis of Eutrophic Lakes: A case Study in the Netherlands. Int. J. Remote Sens. 1993, 14, 799-821. [CrossRef]

41. Ritchie, J.C.; Schiebe, F.R.; Cooper, C.M.; Harrington, J.A. Chlorophyll Measurements in the Presence of Suspended Sediment Using Broad Band Spectral Sensors Aboard Satellites. J. Freshw. Ecol. 1994, 9, 197-206. [CrossRef]

42. The Free Dictionary by FARLEX, Sanya. Available online: https://encyclopedia.thefreedictionary.com/Sanya (accessed on 6 June 2014).

43. Li, S.J.; Li, Y.W.; Fan, B.; Gao, X.M.; Xu, X.Q.; Teng, Y.; Ye, Q. Wave Observation and Statistical Analysis in the Southeast Coast of Hainan Island. Adv. Mar. Sci. 2016, 34, 2-9.

44. Bricaud, A.; Stramski, D. Spectral Absorption Coefficients of Living Phytoplankton and Non-Algal Biogenous Matter: A comparison Between the Peru Upwelling Area and the Sargasso Sea. Limnol. Oceanogr. 1990, 35, 562-582. [CrossRef]

45. Xi, H.Y.; Larouche, P.; Michlel, C.; Tang, S.L. Beam Attenuation, Scattering and Backscattering of Marine Particles in relation to Particle Size Distribution and Composition in Hudson Bay (Canada). J. Geophys. Res. Oceans 2015, 120, 3286-3300. [CrossRef]

46. Neil, C.; Cunningham, A.; Mckee, D. Relationships between Suspended Mineral Concentrations and Red-Waveband Reflectances in Moderately Turbid Shelf Seas. Remote Sens. Environ. 2011, 115. [CrossRef]

47. Whitmire, A.L.; Pegau, W.S.; Lee, K.B.; Boss, B.; Cowles, T.J. Spectral Backscattering Properties of Marine Phytoplankton Cultures. Opt. Express 2010, 18, 15073-15093. [CrossRef]

48. Mobley, C.D. Estimation of the Remote-Sensing Reflectance from Above-Surface Measurements. Appl. Opt. 1999, 38, 7442-7455. [CrossRef] [PubMed]

49. Zhang, H.; Voss, K.J. Bidirectional Reflectance Measurements of Sediments in The Vicinity of Lee Stocking Island, Bahamas. Limnol. Oceanogr. 2013, 48, 380-389. [CrossRef]

50. Hu, C.; Muller-Karger, F.E.; Taylor, C.; Carder, K.L.; Kelble, C.; Johns, E.; Heil, C.A. Red Tide Detection and Tracing Using MODIS Fluorescence Data: A Regional Example in SW Florida Coastal Waters. Remote Sens. Environ. 2005, 97, 311-321. [CrossRef]

51. Hu, C.; Lee, Z.; Franz, B. Chlorophyll-a Algorithms for Oligotrophic Oceans: A Novel Approach Based on Three-Band Reflectance Difference. J. Geophys. Res. Oceans. 2012, 117. [CrossRef]

52. Gower, J.; King, S.; Yan, W.; Borstad, G.; Brown, L. Use of the 709 nm Band of MERIS to Detect Intense Plankton Blooms and Other Conditions in Coastal Waters. Eur. Space Agency 2005, 31.

53. Gitelson, A.A.; Guilin, D.; Moses, W.J.; Barrow, T. A Bio-Optical Algorithm for the Remote Estimation of the Chlorophyll-A Concentration in Case 2 Waters. Environ. Res. Lett. 2009, 4, 045003. [CrossRef]

54. Gordon, H.R.; Brown, J.W.; Brown, O.B.; Evans, R.H.; Smith, R.C. A Semi-Analytic Radiance Model of Ocean Color. J. Geophys. Res. Atmos. 1988, 93, 10909-10924. [CrossRef]

55. Park, Y.J.; Ruddick, K. Model of remote-sensing reflectance including bidirectional effects for case 1 and case 2 waters. Appl. Opt. 2005, 44, 1236-1249. [CrossRef]

56. Stramski, D.; Bricaud, A.; Morel, A. Modeling the Inherent Optical Properties of the Ocean Based on the Detailed Composition of the Planktonic Community. Appl. Opt. 2001, 40, 2929-2945. [CrossRef]

57. Mitchell, B.G.; Kahru, M.; Wieland, J. Determination of Spectral Absorption Coefficients of Particles, Dissolved Material and Phytoplankton for Discrete Water Samples. Ocean Opt. Protoc. Satell. Ocean Color Sens. Valid. Revis. 2002, 3, 231-257.

58. Smith, R.C.; Baker, K.S. Optical Properties of the Clearest Natural Waters (200-800 nm). Appl. Opt. 1981, 20, 177-184. [CrossRef] [PubMed]

59. Twardowski, M.S.; Claustre, H.; Freeman, S.A.; Stramski, D.; Huot, Y. Optical Backscattering Properties of the "Clearest" Natural Waters. Biogeosciences 2007, 4, 1041-1058. [CrossRef]

60. Antoite, D.; Andre, J.M.; Morel, A. Oceanic Primary Production 2: Estimation of Global Scale from Satellite (Coastal Zone Color Scanner) Chlorophyll. Glob. Biogeochem. Cy. 1996, 10, 57-69. [CrossRef] 
61. McKee, D.; Cunningham, A.; Slater, J.; Jones, K.J.; Griffiths, C.R. Inherent and Apparent Optical Properties in Coastal Waters: A study of the Clyde Sea in Early Summer. Estuar. Coast. Shelf Sci. 2002, 56, 369-376. [CrossRef]

62. McKee, D.; Cunningham, A. Identification and Characterization of Two Optical Water Types in the Irish Sea from in Situ Inherent Optical Properties and Seawater Constituents. Estuar. Coast. Shelf Sci. 2006, 68, 305-316. [CrossRef]

63. Pope, R.M.; Fry, E.S. Absorption Spectrum (380-700 nm) of Pure Water II. Integrating Cavity Measurements. Appl. Opt. 1997, 36, 8710-8723. [CrossRef]

64. Wang, M. A Sensitivity Study of the SeaWiFS Atmospheric Correction Algorithm: Effects of Spectral Band Variations. Remote Sens. Environ. 1999, 67, 348-359. [CrossRef]

65. Adler-Golden, S.M.; Matthew, M.W.; Bernstein, L.S.; Levine, R.Y.; Berk, A.; Richtsmeier, S.C.; Acharya, P.K.; Anderson, G.P.; Felde, G.; Gardner, J.; et al. Atmospheric Correction for Short Wave Spectral Imagery Based on MODTRAN4. SPIE Proc. Imaging Spectr. 1999, 3753, 61-69.

66. Vis, I. Atmosphere Correction Module: QUAC and FLAASH User's Guide. In ITT Visual Information Solutions, 4th ed.; ITT: Boulder, CO, USA, 2009.

67. Rotta, L.H.S.; Alcantara, E.H.; Watanabe, F.S.Y.; Rodrigues, T.W.P.; Imai, N.N. Atmospheric Correction Assessment of SPOT-6 Image and its Influence on Models to Estimate Water Column Transparency in Tropical Reservoir. Remote Sens. Appl. Soc. Environ. 2016, 4, 158-166. [CrossRef]

68. Lu, T.Q.; Chen, S.B.; Tu, Y.; Yu, Y.; Cao, Y.J.; Jiang, D.Y. Comparative Study on Coastal Depth Inversion Based on Multi-source Remote Sensing Data. Chin. Geogr. Sci. 2019, 29, 192-201. [CrossRef]

69. Chen, Q.D.; Deng, R.R.; QIN, Y.; Xiong, L.H.; He, Y.Q. Analysis of Spectral Characteristics of Coral Under Different Growth Patterns. Acta Ecol. Sin. 2015, 35, 3394-3402.

70. Carlson, R.E. A Trophic State Index for Lakes. Limnol. Oceanogr. 1977, 22, 361-369. [CrossRef]

71. Lamparelli, M.C. Graus De Trofia Em Corpos D'Água Do Estado De São Paulo. Ph.D. Thesis, University of São Paulo, São Paulo, Brazil, 2004.

72. Ocean Color Web. Available online: http://oceancolor.gsfc.nasa.-gov/ANALYSIS/ocv6/ (accessed on 6 June 2014).

73. Tassan, S. Local Algorithms Using SeaWiFS data for the Retrieval of Phytoplankton, Pigments, Suspended Sediment, and Yellow Substance in Coastal Waters. Appl. Opt. 1994, 33, 2369-2378. [CrossRef] [PubMed]

74. Kallio, K. Optical Properties of Finnish Lakes Estimated with Simple Bio-Optical Models and Water Quality Monitoring Data. Hydrol. Res. 2006, 37, 183-204. [CrossRef]

75. Brezonik, P.; Olmanson, L.; Finlay, J.; Bauer, M. Factors Affecting the Measurement of CDOM by Remote Sensing of Optically Complex Inland Waters. Remote Sens. Environ. 2015, 157, 199-215. [CrossRef]

76. Ana, R.; Martin, H.; Gonzalo, M.G.; Sampsa, K.; Kari, K.; Gustau, C.V. Machine Learning Regression Approaches for Colored Dissolved Organic Matter (CDOM) Retrieval with S2-MSI and S3-OLCI Simulated Data. Remote Sens. 2018, 10, 786.

77. Bricaud, A.; Morel, A.; Prieur, L. Absorption by Dissolved Organic Matter of the Sea (YELLOW SUBSTANCE) in the UV and Visible Domains. Limnol. Oceanogr. 1981, 26, 43-53. [CrossRef]

78. Song, K.S.; Shang, Y.X.; Wen, Z.D.; Jacinthe, P.A.; Liu, G.; Lyu, L.L.; Fang, C. Characterization of CDOM in Saline and Freshwater Lakes Across China Using Spectroscopic Analysis. Water Res. 2019, 150, 403-417. [CrossRef]

(C) 2020 by the authors. Licensee MDPI, Basel, Switzerland. This article is an open access article distributed under the terms and conditions of the Creative Commons Attribution (CC BY) license (http://creativecommons.org/licenses/by/4.0/). 